\title{
EULAR recommendations for the management of rheumatoid arthritis with synthetic and biological disease-modifying antirheumatic drugs: 2019 update
}

Josef S Smolen (1) , ${ }^{1}$ Robert B M Landewé, ${ }^{2,3}$ Johannes W J Bijlsma, ${ }^{4}$ Gerd R Burmester, ${ }^{5}$ Maxime Dougados, ${ }^{6}$ Andreas Kerschbaumer $\quad(1),{ }^{1}$ lain B McInnes, Alexandre Sepriano (1), ${ }^{8}$ Ronald F van Vollenhoven, ${ }^{9}$ Maarten de Wit (ㄷ, ${ }^{10}$ Daniel Aletaha, ${ }^{1}$ Martin Aringer (1) , ${ }^{11}$ John Askling, ${ }^{12}$ Alejandro Balsa, ${ }^{13}$

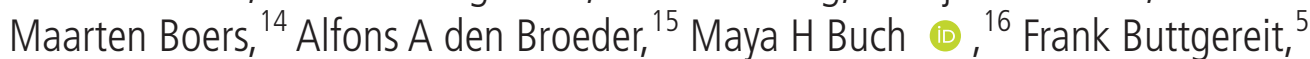
Roberto Caporali, ${ }^{17}$ Mario Humberto Cardiel, ${ }_{18}^{18}$ Diederik De Cock, ${ }^{19}$ Catalin Codreanu, ${ }^{20}$ Maurizio Cutolo (1) ${ }^{21}$ Christopher John Edwards, ${ }^{22}$

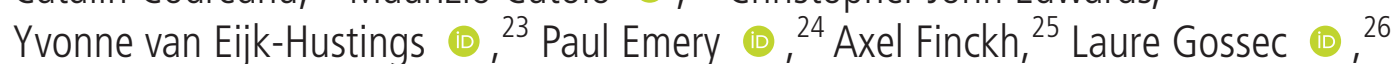
Jacques-Eric Gottenberg, ${ }^{27}$ Merete Lund Hetland ${ }_{1}^{28}$ Tom W J Huizinga (1) ${ }^{29}$ Marios Koloumas, ${ }^{30,31}$ Zhanguo Li, ${ }^{32}$ Xavier Mariette, ${ }^{33}$ Ulf Müller-Ladner, ${ }_{1}^{34}$ Eduardo F Mysler, ${ }^{35}$ Jose A P da Silva (1), ${ }^{36}$ Gyula Poór, ${ }^{37}$ Janet E Pope (ㅇ, ${ }^{38}$ Andrea Rubbert-Roth $\odot{ }^{39}$ Adeline Ruyssen-Witrand, ${ }^{40}$ Kenneth G Saag, ${ }^{41}$ Anja Strangfeld ${ }^{42}$ Tsutomu Takeuchi, $^{43}$ Marieke Voshaar, ${ }^{44}$ René Westhovens, ${ }^{19}$ Désirée van der Heijde ${ }^{20}{ }^{29}$

\section{Handling editor Dimitrios T Boumpas \\ For numbered affiliations see end of article.}

\section{Correspondence to} Professor Josef S Smolen, Division of Rheumatology, Department of Medicine 3, Medical University of Vienna, Vienna A-1090, Austria; josef.smolen@meduniwien.ac.at

JSS and RBML contributed equally.

JSS and RBML are joint first authors.

Received 17 November 2019 Revised 16 December 2019 Accepted 18 December 2019 Published Online First 22 January 2020

Check for updates

(C) Author(s) (or their employer(s)) 2020. No commercial re-use. See rights and permissions. Published by BMJ.

To cite: Smolen JS Landewé RBM, Bij|sma JWJ et al. Ann Rheum Dis 2020;79:685-699.

\section{ABSTRACT}

Objectives To provide an update of the European League Against Rheumatism (EULAR) rheumatoid arthritis (RA) management recommendations to account for the most recent developments in the field.

Methods An international task force considered new evidence supporting or contradicting previous recommendations and novel therapies and strategic insights based on two systematic literature searches on efficacy and safety of disease-modifying antirheumatic drugs (DMARDs) since the last update (2016) until 2019. A predefined voting process was applied, current levels of evidence and strengths of recommendation were assigned and participants ultimately voted independently on their level of agreement with each of the items.

Results The task force agreed on 5 overarching principles and 12 recommendations concerning use of conventional synthetic (cs) DMARDs (methotrexate (MTX), leflunomide, sulfasalazine); glucocorticoids (GCs); biological (b) DMARDs (tumour necrosis factor inhibitors (adalimumab, certolizumab pegol, etanercept, golimumab, infliximab), abatacept, rituximab, tocilizumab, sarilumab and biosimilar (bs) DMARDs) and targeted synthetic (ts) DMARDs (the Janus kinase (JAK) inhibitors tofacitinib, baricitinib, filgotinib, upadacitinib). Guidance on monotherapy, combination therapy, treatment strategies (treat-to-target) and tapering on sustained clinical remission is provided. Cost and sequencing of b/tsDMARDs are addressed. Initially, MTX plus GCs and upon insufficient response to this therapy within 3 to 6 months, stratification according to risk factors is recommended. With poor prognostic factors (presence of autoantibodies, high disease activity, early erosions or failure of two csDMARDs), any bDMARD or JAK inhibitor should be added to the CSDMARD. If this fails, any other bDMARD (from another or the same class) or tsDMARD is recommended. On sustained remission, DMARDs may be tapered, but not be stopped. Levels of evidence and levels of agreement were mostly high.

Conclusions These updated EULAR recommendations provide consensus on the management of RA with respect to benefit, safety, preferences and cost.

The European League Against Rheumatism (EULAR) developed its first recommendations for the management of rheumatoid arthritis (RA) with synthetic and biological disease-modifying antirheumatic drugs (DMARDs) in 2010. ${ }^{1}$ They summarised the state of the art and provided rheumatologists, patients, payers and other stakeholders with the evidence-based views of European experts on the optimal use and sequence of pharmaceutical therapies in patients with RA. Over the course of the decade, the development of new classification criteria for $\mathrm{RA}^{2}$; novel information on optimal clinical targets, such as the American College of Rheumatology (ACR)-EULAR remission definitions $^{3}$; evolution of treatment algorithms and strategies ${ }^{45}$ and the advent of new drugs ${ }^{67}$ already necessitated two updates of the EULAR recommendations. ${ }^{8}$ The ACR, the Asian-Pacific League of Associations for Rheumatology (APLAR) and the Pan-American League of Associations for Rheumatology (PANLAR) have published similar guidance documents, although using slightly different approaches. $^{10-12}$

Today it is widely accepted that clinical remission is the main therapeutic target for patients with RA, 
with low disease activity (LDA) as a best possible alternative, and that a treat-to-target (T2T) strategy should be applied when treating patients with RA. ${ }^{19-11}$

Although relevant data accrue rapidly, several of the recommendations, even in the 2016 update, were based on rather low levels of evidence (LoE) and many have elicited intense debates because of variable interpretations of evidence and empirical approaches. Three years have passed since the last update. ${ }^{9}$ Therefore, it was considered timely to again evaluate information regarding:

- Newly licensed drugs

- Long-term efficacy and safety of long approved agents

- Comparative effectiveness studies

- Therapeutic targets and treatment strategies

- Consideration of safety aspects and costs

- Specific items of the 2016 research agenda that have been accomplished during the last few years of the decade

The EULAR executive committee approved the proposal to update the recommendations. We wished to obtain global input and account for views from regions of the world beyond Europe and invited rheumatologists from Asia, Latin America and North America to contribute to the discussion and phrasing of the recommendations.

The major focus of the EULAR recommendations continues to be pharmacological therapy with DMARDs. The concept of 'disease modification' comprises a combination of relief of signs and symptoms; improvement or normalisation of physical function, quality of life and social and work capacity; and most characteristically the inhibition of occurrence or progression of structural damage to cartilage and bone. The latter distinguishes DMARDs from mere symptomatic agents, such as non-steroidal antirheumatic drugs.

The increasing number of effective drugs and modes of action (MOAs) has improved the likelihood of reaching the treatment target for individuals with RA, but high drug-costs still limit widespread use and thus contribute to inequity of access to best care across various regions and countries. ${ }^{13-15}$ The approval and advent of biosimilar (bs) DMARDs has introduced price competition and led to a considerable reduction of the net costs of biological (b) DMARDs, ${ }^{16}$ although this may not be true in all countries and may require further exploration. Nevertheless, access to optimal care is usually poor in low-income countries, but even in some affluent countries payers still do not adhere to otherwise widely established standards of care. ${ }^{17} 18$ Therefore, recommendations for the management of patients with RA have become increasingly useful in providing physicians, patients, health professionals, payers, regulators and others involved in healthcare with evidence-based guidance supported by the views of experts involved in generating these novel developments. Consequently, from their outset, EULAR recommendations always addressed cost aspects. ${ }^{1}$ Indeed, in the recently updated EULAR standardised operating procedures (SOPs) on the development of recommendations, cost aspects have been included in addition to requiring the assessment of evidence on efficacy and safety as well as expert opinion. ${ }^{19}$ This is in line with recommendations by the $\mathrm{WHO}$ on rational treatment. ${ }^{20}$

Herein, we provide the 2019 update of the EULAR RA management recommendations.

\section{METHODS}

After approval by the EULAR executive committee, the convener (JSS) and methodologist (RBML) invited a steering committee and a task force to work on this update of the EULAR recommendations for the management of RA. The 2019 update followed the EULAR SOPs for the development of recommendations ${ }^{19}$ which also suggest adherence to the Appraisal of Guidelines for Research \& Evaluation (AGREE) recommendations in their updated version (AGREE II). ${ }^{21}$

\section{Steering committee}

The steering committee included eight rheumatologists (JWJB, GB, MD, RBML, IBM, JSS, RFvV, DvdH), one patient representative (MdW) and two fellows (AK, AS) who performed the systematic literature research (SLR). This group initially developed the respective research questions. The SLRs focused on (1) efficacy of DMARDs (as monotherapy or combination therapy, including conventional synthetic (cs) DMARDs, bDMARDs and targeted synthetic (ts) DMARDs), glucocorticoids (GC) and treatment strategies and (2) safety of DMARDs and GC. To this end, the SLRs obtained in $2016^{22-24}$ served as a starting point and a systematic analysis of the literature published between 2016 and 8 March 2019 was performed. New information on treatment strategies was also evaluated. In contrast to the previous safety SLR which focused on registry data, the current safety SLR also addressed data from randomised controlled trials and extension studies, since for many new agents registry data are still limited. Formal economic analyses were not performed, but cost aspects were considered throughout the process in line with the current state of the art of developing recommendations. ${ }^{20}{ }^{25}$ The two rheumatology fellows exploited existing publication databases on randomised controlled trials for efficacy and safety, and also evaluated recent EULAR and ACR congress abstracts. Summaryof-findings tables were generated, a thorough risk-of-bias assessment was performed (for details, see the publications on these SLRs) ${ }^{26} 27$ and LoE and strengths of recommendation (SoR) were determined with the standards of the Oxford Centre for Evidence Based Medicine. ${ }^{28}$ The two SLRs informing the task force and a detailed description of their methods are published separately. ${ }^{26}{ }^{27}$ Of note, in the present publication we also use references from the 2019 Annual European Congress held in June 2019 where it deemed appropriate, or publications that appeared after the deadline of the SLRs, 8 March 2019, when the contents had previously been covered by abstracts addressed in the SLRs, or otherwise newly published information regarding efficacy and especially safety that deemed important to be included as up-to-date information for the readers at the time of submission.

The steering committee discussed the results of the SLRs thoroughly and formulated proposals for an update of the recommendations based on this information. The SLR data and the suggestions of the steering committee were presented to the whole task force for further discussion, development of the updated recommendations and voting.

\section{Task force}

The task force consisted of 47 individuals, including the steering committee members. Among the task force members were three patients, two health professionals and two delegates of the EULAR young rheumatologists' network EMEUNET. The rheumatologists were all experienced in the treatment of RA and most had previously participated in clinical trials; moreover, several of them were involved in the analysis of data from their countries' patient registries or in various aspects of outcomes research. The patients and health professionals all had a track record of participating in consensus finding activities, like most of the rheumatologists. Since we also wished the task force's work to be informed 
by rheumatologists from other regions of the world, aside from a broad representation from 15 European countries, two rheumatologists from Asia, two from Latin America and two from North America participated; most had actively engaged in developing documents of their regional leagues and/or national societies. All task force members disclosed their potential conflicts of interest to the EULAR executive committee before the start of the process.

\section{Consensus finding}

A few principal considerations were specified upfront. First, the previous 2016 version of the recommendations (containing 4 overarching principles and 12 recommendations) were key considerations, ${ }^{9}$ but were all open to amendment, changes in ordering or deletion where appropriate. Second, it was decided that existing recommendations should be discussed in the context of new evidence. If new evidence contradicting a previous recommendation was lacking, the former evidence base had to be accepted and the recommendation had to be kept unchanged. This approach prevents the intentional or unintentional neglect of previous formal task force decisions, which had been based on a thorough discussion of existing evidence presented at that time, recalibrated and sometimes amended at update procedures; also, they have always been endorsed by voting among the previous task force members followed by EULAR's executive committee approval. Third, drugs not (yet) approved in Europe but used elsewhere in the world, and unapproved drugs with evidence from phase III clinical trials could be considered in the recommendations to allow for some anticipation of a potential future uptake in clinical practice, appreciating all respective caveats. Importantly, drugs can only legally be prescribed after their regulatory approval. Also, whereas the recommendations address some safety aspects, the readers are referred to the summaries of product characteristics (SPCs) for more detailed safety information for each of the drugs. Fourth, registry data were primarily used for the assessment of rare safety issues but not efficacy, since the outcomes of patients included in registries are often confounded by indication.

After the presentation of the SLR results and the steering committee's proposals for the amendment of the recommendations, the task force was divided into three breakout groups. One group reviewed new evidence related to treatment strategies and targets, focusing also on the overarching principles; the second group addressed new evidence regarding bDMARDs and tsDMARDs and the third group dealt with new evidence in relation to the use of csDMARDs (monotherapy or in combinations) and GC. Respective safety aspects were addressed in each of these breakout groups.

After representatives of each breakout group had reported the results of the respective discussions and presented proposals for the wording of individual recommendations to the whole task force for further deliberations, voting took place.

For a change of an existing overarching principle or recommendation to be accepted for the final document, a majority of $\geq 75 \%$ of the votes was required. Once such change was accepted, wording details could undergo further voting. A new recommendation was immediately accepted when $\geq 75 \%$ or more of the task force members voted for it. If this result was not achieved, the respective text was amended and subjected to a second ballot, for which a $67 \%$ majority was required. If this ballot was not successful, the text was further amended and subjected to a third ballot for which a simple $(>50 \%)$ was required; failing that, the proposal was rejected. For new or amended items, the results of the respective last ballot are shown as percentage of voting members. Notes captured the contents of the discussions and the reasoning behind each decision and these are presented in the comments accompanying the individual items. At every point in time, more than $90 \%$ of the members participated in the ballots; the percentages shown always relate to per cent of present participants in that vote.

After the face-to-face meeting, each recommendation, as agreed by the task force, received the appropriate LoE and strength of recommendation based on the SLRs. With this information added, the recommendations were subjected to an anonymous electronic assessment (by email) on the levels of agreement (LoA). Each recommendation received an assessment on a scale of $0-10$ with 0 meaning no agreement whatsoever and 10 full agreement; the mean values of these votes are presented.

The draft of the manuscript was sent to all task force members for their comments. After incorporation of these comments, the manuscript was submitted to the EULAR executive committee for review and approval. The comments obtained from the executive committee were also addressed, and the final version of the manuscript was then submitted to the journal for peer review.

\section{RESULTS}

The 2019 update of the EULAR RA management recommendations reflects the balance of clinical, functional and structural efficacy; safety; costs; and patients' perceptions as evaluated by the task force. Drug toxicity was discussed and considered, but the respective data are presented primarily in the safety SLR, ${ }^{26}$ because it is assumed that prescribers should be aware of the safety information provided in the SPCs of the various agents. EULAR has developed a series of documents addressing safety of drugs used for the treatment of RA, ${ }^{29-35}$ and various other publications have focused on these aspects. ${ }^{36-42}$ In particular, as suggested by the safety SLR, the major risk of bDMARDs and tsDMARDs is related to infections. Recommendations for vaccination ${ }^{33}$ as well as a score allowing calculation of the risk of infection in patients exposed to bDMARDs have been developed. ${ }^{41} 4344$ Nevertheless, when toxicity constitutes a major or unexpected problem, a specific warning is provided in this document. Of note, the two SLRs ${ }^{26}{ }^{27}$ as well as the text accompanying each item should be regarded as part and parcel of these recommendations, since the individual bullet points represent only abbreviated versions of the discussions and conclusions.

When classifying DMARDs, the task force adhered to the previously used nomenclature ${ }^{84}$ as shown in table 1 . This table also provides a glossary of terms employed in the present document. The task force did not distinguish between early and established RA but rather between three phases of the treatment process by differentiating between patients who are naive to any DMARD therapy (phase I), patients who had an insufficient response (IR) to initial course(s) of csDMARDs (phase II) and those who had an IR to a first bDMARD or tsDMARD (phase III). There is currently no evidence for differential responses solely based on disease duration, apart from differences in baseline damage due to delayed treatment initiation and consequent risk of damage progression. The task force also took prognostic factors (table 1) into account, which have similar predictive power irrespective of disease duration. ${ }^{46} 47$ Of note, recommendations for the management of early arthritis, including undifferentiated arthritis, have been updated recently. ${ }^{48}$ The present recommendations do not address the management of patients with undifferentiated arthritis or arthralgia in patients who may 


\begin{tabular}{|c|c|c|}
\hline Term & \multicolumn{2}{|l|}{ Definition } \\
\hline Poor prognostic factors & \multicolumn{2}{|c|}{$\begin{array}{l}\text { Persistently moderate or high disease activity } \\
\text { despite conventional synthetic DMARD (csDMARD) } \\
\text { therapy according to composite measures including } \\
\text { joint counts } \\
\text { High acute phase reactant levels } \\
\text { High swollen joint count } \\
\text { Presence of RF and/or ACPA, especially at high } \\
\text { levels } \\
\text { Presence of early erosions } \\
\text { Failure of two or more csDMARDs }\end{array}$} \\
\hline Low-dose glucocorticoids & \multicolumn{2}{|c|}{$<7.5 \mathrm{mg} /$ day (prednisone equivalent) } \\
\hline Tapering & \multicolumn{2}{|c|}{$\begin{array}{l}\text { Reduction of drug dose or increase of application } \\
\text { interval } \\
\text { May include cessation (tapering to } 0 \text { ), but then only } \\
\text { after slow reduction }\end{array}$} \\
\hline Cessation, stopping & \multicolumn{2}{|c|}{ - Stopping of a particular drug } \\
\hline \multicolumn{3}{|l|}{ Disease activity states } \\
\hline Remission & \multicolumn{2}{|c|}{$\begin{array}{l}\text { ACR-EULAR remission definition (Boolean or index } \\
\text { based) }\end{array}$} \\
\hline Low disease activity & \multicolumn{2}{|c|}{$\begin{array}{l}\text { Low disease activity state according to any of the } \\
\text { validated composite disease activity measures that } \\
\text { include joint counts }\end{array}$} \\
\hline $\begin{array}{l}\text { Moderate, high disease } \\
\text { activity }\end{array}$ & \multicolumn{2}{|c|}{$\begin{array}{l}\text { Respective disease activity state according to any of } \\
\text { the validated composite disease activity measures that } \\
\text { include joint counts }\end{array}$} \\
\hline \multicolumn{3}{|l|}{ DMARD nomenclature } \\
\hline \multirow[t]{2}{*}{ Synthetic DMARDs } & csDMARDs & $\begin{array}{l}\text { Eg, methotrexate, } \\
\text { leflunomide, sulfasalazine, } \\
\text { hydroxychloroquine }\end{array}$ \\
\hline & $\begin{array}{l}\text { Targeted synthetic } \\
\text { DMARDs }\end{array}$ & $\begin{array}{l}\text { Eg, baricitinib, tofacitinib, } \\
\text { upadacitinib }\end{array}$ \\
\hline \multirow[t]{2}{*}{ Biological DMARDs } & $\begin{array}{l}\text { Biological originator } \\
\text { DMARDs }\end{array}$ & $\begin{array}{l}\text { TNFi: adalimumab, } \\
\text { certolizumab, etanercept, } \\
\text { golimumab, infliximab; IL- } \\
\text { 6Ri: sarilumab, tocilizumab; } \\
\text { Costimulation-i: abatacept; } \\
\text { anti-B cell (CD20): } \\
\text { rituximab }\end{array}$ \\
\hline & Biosimilar DMARDs & $\begin{array}{l}\text { (currently for: adalimumab, } \\
\text { etanercept, infliximab, } \\
\text { rituximab) }\end{array}$ \\
\hline
\end{tabular}

ACPA, anticitrullinated protein antibody; ACR, American College of Rheumatology; CS, conventional synthetic; DMARDs, disease-modifying antirheumatic drugs; EULAR, European League Against Rheumatism; IL-6Ri, interleukin 6 receptor inhibitor; RF, rheumatoid factor; TNFi, tumour necrosis factor inhibitor.

be at risk of developing RA, but only patients with RA from the time of diagnosis.

\section{Overarching principles}

As before, the task force reinforced the necessity to adhere to some general principles when treating patients with RA, the so-called overarching principles (table 2). These principles constitute the foundation on which the actual recommendations are based. By their common sense nature, they cannot be based on specific scientific evidence. Until 2013, there were three overarching principles; in 2016, the task force added a fourth one as overarching principle B. Now yet another item appeared necessary as overarching principle $\mathrm{D}$, resulting in five overarching principles for the 2019 update (table 2).

A. Treatment of patients with RA should aim at the best care and must be based on a shared decision between the patient and the rheumatologist. This principle remained unchanged in wording and placement. During discussion, the importance of shared decision-making was reiterated and the importance of patient education emphasised. Indeed, patient education may increase adherence to medication ${ }^{49}$; moreover, education of rheumatologists may foster adherence to appropriate assessment strategies. ${ }^{50}$ There were suggestions made to expand this item by mentioning the importance of patient education separately, but there was ultimate agreement that patient education forms the implicit and inseparable basis for shared decision-making. Nevertheless, since shared decisionmaking is so important, communication skills should also be a focus of rheumatologists and other health professionals. This item is also included in a publication on quality indicators that should be incorporated in the decision process. ${ }^{51}$ It should also be noted that the focus of the task force was on DMARDs and not on other pharmacological and nonpharmacological therapies which may have to be considered in many patients as adjunctive therapies for best care. The task force agreed at a level of 9.7 (SD 1.1) with this principle.

B. Treatment decisions are based on disease activity, safety issues and other patient factors, such as comorbidities and progression of structural damage. Added in 2016 and remaining unchanged, this principle is particularly important when considering the use of bDMARDs and tsDMARDs. The higher risk of herpes zoster infections on JAK-inhibitors, more pronounced in some Asian countries such as Japan and South Korea, is captured under this principle. The prevalent discussion on the risk of venous thromboembolic events (VTEs), such as in relation to obesity or a history of prior VTE events, has also been addressed. ${ }^{5253}$ To this end, there was a debate about whether the term 'risk' should be more explicitly added to this overarching principle, but it was then agreed that the terms 'comorbidities and safety issues' inherently include risk assessment, and obesity, for example, also constitutes a comorbidity. It was decided to mention these deliberations in the explanatory text and leave the principle unchanged. LoA 9.8 (0.5).

C. Rheumatologists are the specialists who should primarily care for patients with $R A$. Unchanged from previous recommendations, this principle addresses the importance of specialty care for a complex disease like RA, ${ }^{54-58}$ since rheumatologists possess the optimal depth and breadth of experience regarding the use of all types of DMARDs, including efficacy outcomes, risk assessment and knowledge of comorbidities (as discussed under item B). Importantly, health professionals such as rheumatology nurse specialists also take care of many aspects related to the management of RA and patient education. The rheumatologist often leads a multidisciplinary team in the course of providing 'best care' in accordance with item A. On the other hand, in certain areas of the world rheumatology training is not sufficiently available and other experts may care for patients with RA, hence the term 'primarily'. Moreover, some comorbidities, such as chronic hepatitis, interstitial lung disease or cardiovascular events, may require consultation with, and treatment by, other specialists. Together with item $\mathrm{D}$, this principle achieved the highest $L o A$ 9.9 (0.4).

D. Patients require access to multiple drugs with different MOAs to address the heterogeneity of $R A$; they may require multiple successive therapies throughout life. Developing this new overarching principle was considered necessary and timely, in view of the increasing number of drugs available to treat RA. We now recognise five molecular target families (tumour necrosis factor (TNF), interleukin 6 (IL-6), CD80/86, CD20 and Janus kinases (JAK)) with multiple drugs for several of 
Table 2 The 2019 updated EULAR RA management recommendations

\begin{tabular}{|c|c|c|c|c|}
\hline & Overarching principles & LoE & SoR & LoA \\
\hline A & $\begin{array}{l}\text { Treatment of patients with RA should aim at the best care and must be based on a shared decision between } \\
\text { the patient and the rheumatologist. }\end{array}$ & n.a. & n.a. & 9.7 \\
\hline B & $\begin{array}{l}\text { Treatment decisions are based on disease activity, safety issues and other patient factors, such as comorbidities } \\
\text { and progression of structural damage. }\end{array}$ & n.a. & n.a. & 9.8 \\
\hline C & Rheumatologists are the specialists who should primarily care for patients with RA. & n.a. & n.a. & 9.9 \\
\hline D & $\begin{array}{l}\text { Patients require access to multiple drugs with different modes of action to address the heterogeneity of RA; } \\
\text { they may require multiple successive therapies throughout life. }\end{array}$ & n.a. & n.a. & 9.9 \\
\hline \multirow[t]{2}{*}{$\mathrm{E}$} & $\begin{array}{l}\text { RA incurs high individual, medical and societal costs, all of which should be considered in its management by } \\
\text { the treating rheumatologist. }\end{array}$ & n.a. & n.a. & 9.4 \\
\hline & Recommendations & & & \\
\hline 1. & Therapy with DMARDs should be started as soon as the diagnosis of RA is made. & $1 a$ & A & 9.8 \\
\hline 2. & Treatment should be aimed at reaching a target of sustained remission or low disease activity in every patient. ${ }^{*}$ & $1 \mathrm{a}$ & A & 9.7 \\
\hline 3. & $\begin{array}{l}\text { Monitoring should be frequent in active disease (every } 1-3 \text { months); if there is no improvement by at most } \\
3 \text { months after the start of treatment or the target has not been reached by } 6 \text { months, therapy should be } \\
\text { adjusted. }\end{array}$ & $2 b$ & B & 9.3 \\
\hline 4. & MTX should be part of the first treatment strategy. & $1 a$ & A & 9.4 \\
\hline 5. & $\begin{array}{l}\text { In patients with a contraindication to MTX (or early intolerance), leflunomide or sulfasalazine should be } \\
\text { considered as part of the (first) treatment strategy. }\end{array}$ & $1 \mathrm{a}$ & A & 9.0 \\
\hline 6. & $\begin{array}{l}\text { Short-term glucocorticoids should be considered when initiating or changing csDMARDs, in different dose } \\
\text { regimens and routes of administration, but should be tapered as rapidly as clinically feasible. }\end{array}$ & $1 \mathrm{a}$ & A & 8.9 \\
\hline 7. & $\begin{array}{l}\text { If the treatment target is not achieved with the first csDMARD strategy, in the absence of poor prognostic } \\
\text { factors*, other csDMARDs should be considered. }\end{array}$ & 5 & D & 8.4 \\
\hline 8. & $\begin{array}{l}\text { If the treatment target is not achieved with the first csDMARD strategy, when and poor prognostic factors* are } \\
\text { present, a bDMARD† or a tsDMARD } \ddagger \text { should be added. }\end{array}$ & $1 a$ & A & 9.3 \\
\hline 9. & $\begin{array}{l}\text { bDMARDs and tsDMARDs should be combined with a cSDMARD; in patients who cannot use csDMARDs } \\
\text { as comedication, IL-6 pathway inhibitors and tsDMARDs may have some advantages compared with other } \\
\text { bDMARDs. }\end{array}$ & $1 \mathrm{a}$ & A & 8.9 \\
\hline 10. & $\begin{array}{l}\text { If a bDMARD" or tsDMARD }{ }^{\# \#} \text { has failed, treatment with another bDMARD }+ \text { or a tsDMARD } \ddagger \text { should be } \\
\text { considered; if one TNF inhibitor therapy has failed, patients may receive an agent with another mode of action } \\
\text { or a second TNF inhibitor. }\end{array}$ & $\begin{array}{l}\# 1 \mathrm{~b} \\
\# \#_{5}\end{array}$ & $\begin{array}{l}\text { A } \\
\text { D }\end{array}$ & 8.9 \\
\hline 11. & $\begin{array}{l}\text { If a patient is in persistent remission after having tapered glucocorticoids, one can consider tapering bDMARDs } \\
\text { or tsDMARDs, especially if this treatment is combined with a csDMARD. }\end{array}$ & $1 \mathrm{~b}$ & A & 9.2 \\
\hline 12. & If a patient is in persistent remission, tapering the csDMARD could be considered. & $2 \mathrm{~b}$ & B & 9.0 \\
\hline
\end{tabular}

*For definitions of remission, low disease activity and poor prognostic factors, see table 1.

†Abatacept, rituximab, sarilumab, tocilizumab and TNF inhibitors: adalimumab, certolizumab pegol, etanercept, golimumab,infliximab (whether boDMARDs or EMA-approved/ FDA-approved bsDMARDs).

łJanus kinase inhibitors.

bDMARDs, biological DMARDs; boDMARDs, biological originator DMARDs; bsDMARD, biosimilar DMARDs; csDMARDs, conventional synthetic DMARDs; DMARDs, diseasemodifying antirheumatic drugs; EMA, European Medicines Agency; EULAR, European League Against Rheumatism; FDA, Food and Drug Administration; IL-6, interleukin 6; JAK, Janus kinase; LoA, levels of agreement; LoE, levels of evidence (according to the standards of the Oxford Centre for Evidence Based Medicine); MTX, methotrexate; $n$.a., not applicable; RA, rheumatoid arthritis; SoR, strengths of recommendation; TNF, tumour necrosis factor; tsDMARDs, targeted synthetic DMARDs (currently Janus kinase inhibitors).

these molecules. Treating toward a target of remission or LDA (see recommendations 2 and 3) potentially requires switching between drugs (cycling), sometimes even as early as every 3 months if improvement in accordance with strategic principles (see recommendations 2 and 3 ) is not sufficient. Moreover, it is well established that after failure of one drug, a different drug belonging to the same class, that is, targeting the same molecule, can still be efficacious. Therefore, patients, rheumatologists and payers must be aware that multiple successive drug options are often needed to reach the therapeutic goal. This does not necessarily incur extra cost, since continuing a (partially) failing DMARD can be as costly as switching to another DMARD. This item addresses an additional important characteristic: RA is a lifelong disease whose cause is unknown and which-like many other chronic disorders-cannot currently be cured in most patients, but can be brought into remission or at least LDA in the vast majority of patients with appropriate treatment adaptations using the whole spectrum of therapies available to us today. Thus, remission on drug is the best we can usually achieve, with subsequent dose reduction representing a viable option. While the approach to taper medication is addressed in recommendations 11 and 12, patients, rheumatologists, payers and society must realise that many patients will not be able to stop therapy and may require lifelong treatment. Up to $50 \%$ of patients starting a new DMARD must stop it within 12 to 18 months for insufficient efficacy or adverse events. ${ }^{5960}$ Indeed, many patients still do not reach the therapeutic targets, despite all of our modern therapies and therapeutic strategies, but still about $10 \%-20 \%$ of patients who fail multiple drugs have a good treatment response to yet another agent. ${ }^{61}$ The major weakness of our current treatment approaches is the lack of biomarkers for immediate stratification of an individual patient to the most appropriate drug. Importantly, these considerations emphasise the need to search for predictive markers; however, since a considerable number of patients (about 20\%-30\%) are refractory to all current treatment options, new therapies also need to be developed. Among the task force members, $100 \%$ agreed to add this principle and to its wording and placement. LOA 9.9 (0.4). 
E. RA incurs high individual, medical and societal costs, all of which should be considered in its management by the treating rheumatologist. This (unchanged) principle reminds all stakeholders of an important balance. On the one hand, effective RA therapy can reduce the economic burden on individual patients, their families and society. This economic burden not only includes direct medical costs but also indirect costs due to sick leave, work disability and premature retirement. On the other hand, the high price of many current drugs causes a net increase in the economic burden to society. So when making therapeutic decisions, drugs that are less costly must be preferred over more costly ones, as long as they are similarly efficacious and safe and in line with the therapeutic paradigms. ${ }^{20}$ As mentioned in the introduction, in many countries, the high costs of treatment limit the availability of modern therapies (inequity), ${ }^{14}$ the availability of biosimilars can address this and provide significant reductions of healthcare budgets, when their price is sufficiently low and their application is then reinforced by payers or politicians. ${ }^{16} 62$ The task force voted unanimously to place this item as the last overarching principle, without a change in wording. LoA 9.4 (1.4).

\section{Individual recommendations General aspects}

The task force's discussions resulted in 12 recommendations. The first seven recommendations as well as recommendations 9 and 12 remain unchanged. The background and evidence for these items have been presented previously, and in this respect the reader is referred to the 2016 update. ${ }^{9}$ Each was briefly or more extensively discussed. This was not the case for the aforementioned nine unchanged items. Note that the evidence base was carried forward from last time (or when new data were available adapted accordingly) and that all items whether changed or unchanged underwent a new assessment for the LoA.

As before, the recommendations are ordered in a way that allows their sequential use, and the respective algorithm is depicted in figure 1 . The recommendations start with the approach to patients with newly diagnosed RA, then address both specific drugs and treatment strategies for these patients as well as those who already failed specific therapies, and end with proposals for tapering therapy under appropriate preconditions.

\section{Recommendations}

1. Therapy with DMARDs should be started as soon as the diagnosis of RA is made. This unchanged item represents the basic principle of RA treatment that initiation of DMARD therapy should be immediate, since the disease will not remit spontaneously. LoE 1a, SoR A, LoA 9.8 (0.6).

2. Treatment should be aimed at reaching a target of sustained remission or LDA in every patient (unchanged). This is a central theme in the care of patients with RA, and in line with the T2T recommendations by an international task force. ${ }^{5}$ The instruments that should be used to define remission or LDA were not any more discussed (table 1) and the reader is referred to the $\mathrm{T} 2 \mathrm{~T}$ recommendations and previous deliberations. ${ }^{359}$ Indeed, ACR and EULAR have agreed on the Boolean-based and indexbased remission definitions (the latter using the simplified or clinical disease activity index SDAI, CDAI). ${ }^{3}$ As set forth as principle $\mathrm{A}$, the treatment target has to be agreed in a process of shared decision-making. LoE 1a, SoR A, LoA 9.7 (0.6).

3. Monitoring should be frequent in active disease (every 1-3 months); if there is no improvement by at most 3 months after the start of treatment or the target has not been reached by 6 months, therapy should be adjusted (unchanged). One should consider the desired treatment target as well as various patient factors, including comorbidities, when making treatment adaptations. A rapid attainment of the selected target endpoint is now regarded as being of critical importance: while direct evidence for the question of the best time point for decision-making regarding change of therapy is still lacking, it is known that if disease activity fails to improve by at least $50 \%$ within 3 months, the probability of reaching the treatment goal of remission (or LDA) is low. ${ }^{63}$ Also, the decision to use specific instruments should take into account the direct effects of IL- 6 and JAK inhibitors (JAKis) on the production of acute phase reactants (potentially independent of clinical improvements, but more reflecting pharmacodynamic effects). ${ }^{6566}$ This recommendation remained unchanged. LoE 2b, SoR B, LoA 9.3 (0.8).

4. Methotrexate (MTX) should be part of the first treatment strategy (unchanged). MTX remains the anchor drug in RA; not only is it an efficacious csDMARD by itself but it is also the basis for combination therapies, either with GC or with other csDMARDs, bDMARDs or tsDMARDs. It is important to reiterate that MTX (whether administered orally or subcutaneously) should be escalated to a weekly dose of about $0.3 \mathrm{mg} /$ $\mathrm{kg}^{67}$ and that this escalation should be done within 4-6 weeks. In the Western hemisphere, the optimal therapeutic dose will be around 20-25 mg ${ }^{68}$ per week, while in Asia-in line with a lower body weight and possibly different pharmacogenetics in the East Asian population-the maximum dose will be lower, such as 16 mg in Japan. ${ }^{69}$ The importance of folic acid supplementation is another central aspect of MTX therapy. Patients often associate MTX with a variety of adverse events that are primarily related to its use as medication for malignancies at high doses; therefore, in the course of the shared decision-making process patient education and information, including addressing fears of potential side effects, is as important for this 'old' drug as it is for novel agents.

As in the past, there were some discussions whether the first treatment strategy should already potentially include a bDMARD or tsDMARD, but this was not further pursued since no new evidence has been seen suggesting that the current approachespecially considering recommendation 6-should be changed. Indeed, no bDMARD plus MTX has yet shown superiority compared with MTX plus GC in MTX-naive patients, ${ }^{70} 71$ and tsDMARDs have not yet been compared with MTX plus GC as starting therapy. Moreover, there is no longer-term disadvantage taking this approach, since initiation of MTX in patients with early RA and subsequent addition of a TNF inhibitor (TNFi) at 6 months in case of an IR confers similar overall results as using the combination of MTX and a TNFi from the start, with many patients having already achieved the therapeutic target without the use of a bDMARD. ${ }^{72}$ Thus, this decision was based on both the evidence base regarding efficacy and safety of different initial therapeutic approaches in patients with early RA and on economic considerations. LoE $1 a$, SoR A, LoA 9.4 (1.2).

5. In patients with a contraindication to MTX (or early intolerance), leflunomide or sulfasalazine should be considered as part of the (first) treatment strategy (unchanged). There was a brief discussion whether a direct step to a bDMARD or tsDMARD should be considered if MTX was contraindicated, but no evidence comparing any of these agents in monotherapy with leflunomide or sulfasalazine in combination with GC is currently available. It was also suggested that antimalarials should be added to this recommendation. Indeed, as discussed in previous documents, antimalarials and especially hydroxychloroquine, 


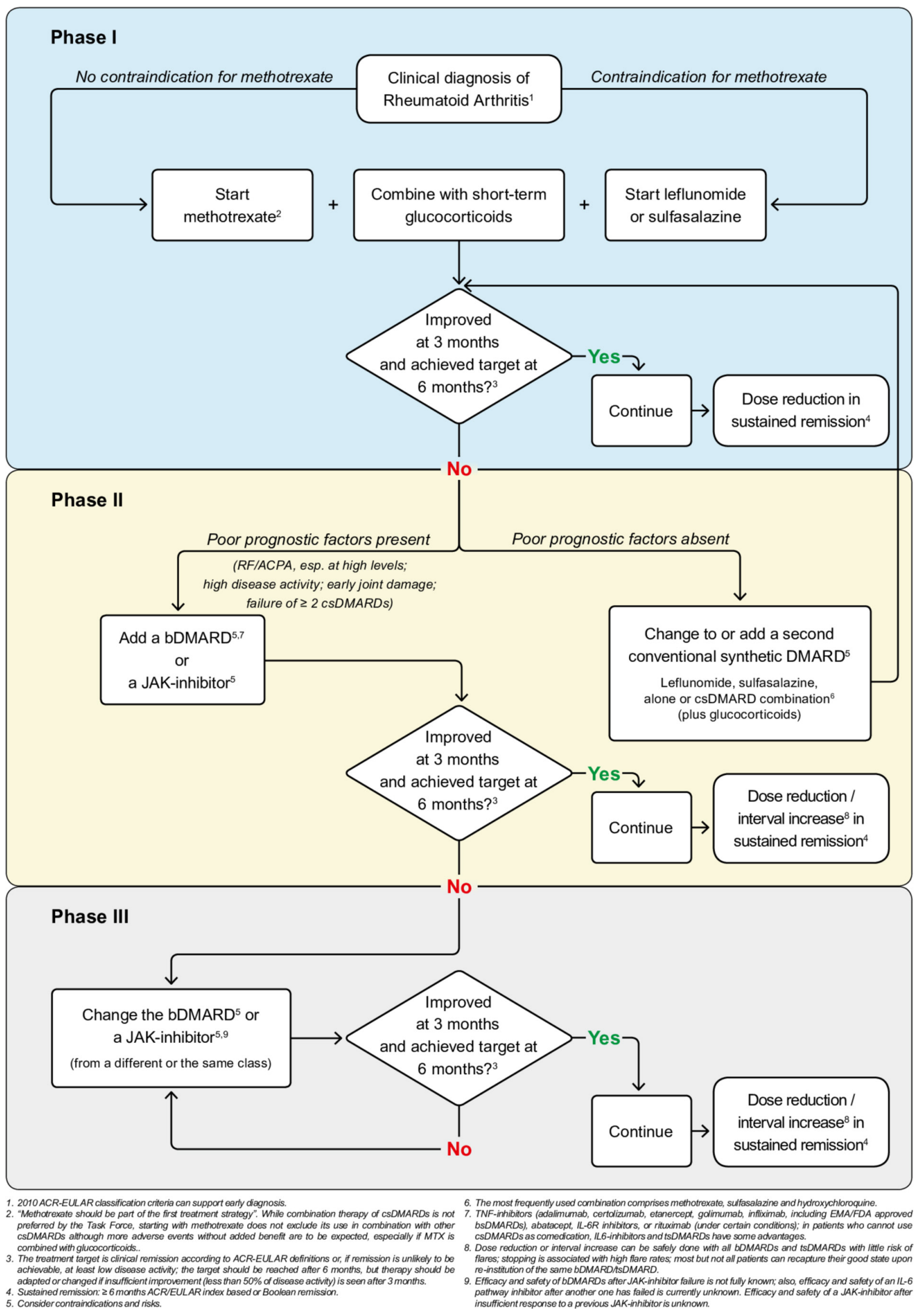

Figure 1 Presentation of the 2019 update of the EULAR RA management recommendations in form of an algorithm. This is an abbreviated version aiming to provide a general overview, but it must be borne in mind that the algorithm cannot be separated from the details presented in the discussion of the individual recommendations in the paper which are part and parcel of these recommendations. ACPA, anticitrullinated protein antibody; ACR, American College of Rheumatology; bDMARDs, biological DMARDs; bsDMARD, biosimilar DMARDs; csDMARDs, conventional synthetic DMARDs; DMARDs, disease-modifying antirheumatic drugs; EMA, European Medicines Agency; EULAR, European League Against Rheumatism; FDA, Food and Drug Administration; IL-6R, interleukin 6 receptor; JAK, Janus kinase; MTX, methotrexate; RA, rheumatoid arthritis; RF,rheumatoid factor; TNF, tumour necrosis factor; tsDMARDs, targeted synthetic DMARDs. 
have a limited place, mainly reserved for patients with mild RA. As no new evidence regarding a good efficacy of hydroxychloroquine was found for RA in general and the historic studies had shown only weak clinical and no structural efficacy, ${ }^{73}$ it was decided to keep the focus on sulfasalazine and leflunomide. In some countries, especially in Asia, also other agents like bucillamine or iguratimod have been approved for RA, but these drugs were not considered here given insufficient data in other regions. LoE 1a, SoR A, LoA 9.0 (1.2).

6. Short-term GC should be considered when initiating or changing csDMARDs, in different dose regimens and routes of administration, but should be tapered as rapidly as clinically feasible (unchanged). There was much less discussion on the use of GC than ever before in the history of these recommendations, and there was unanimity that they should primarily be used as bridging therapy until csDMARDs exhibit their efficacy and that tapering GC rapidly (aiming at discontinuation within about 3 months) is important. Failure to sustain the treatment target on tapering or withdrawal of GC after the bridging phase should be regarded as failure of this therapeutic phase and thus elicit the institution of a bDMARD or a tsDMARD added to the csDMARD. Regarding the debate over whether treatment with bDMARDs or tsDMARDs should be preferred to csDMARDs plus GC, at least three trials have shown similar responses when MTX plus GC was compared with MTX plus bDMARDs ${ }^{70} 7174$ and no new data conflicting with this view have been published since then; tsDMARDs have not yet been compared with MTX plus GC. LoE 1a, SoR A, LoA 8.9 (1.3). ${ }^{707174}$

7. If the treatment target is not achieved with the first csDMARD strategy, in the absence of poor prognostic factors, other csDMARDs should be considered (unchanged). Poor prognostic factors were defined many years ago and are shown in table 1 . They include high disease activity, presence of erosions and autoantibody positivity at high titres, but also failure to achieve LDA after the application of at least two csDMARDs. It was suggested that failure of an initial treatment with MTX plus GC was also included in this list; however, this proposal did not find sufficient backing by the task force. Since the addition of GC both to a first csDMARD and to a subsequent csDMARD therapy is highly recommended (see item 6: 'or changing csDMARDs'), consideration of 'other csDMARDs' here means either switching to or addition of another csDMARD. As detailed in 2016, combinations of csDMARDs are not regarded as superior to MTX monotherapy by the task force, especially if MTX is combined with GC. ${ }^{75}$ One study (CareRA) evaluated patients with early RA with high and low risk and showed that a milder intervention (MTX compared with MTX+GC) also resulted in similar outcomes, ${ }^{75}$ but there are no studies available that have evaluated such a strategy in patients who have failed MTX. On the other hand, it is known that patients who fail MTX often do respond to a subsequent csDMARD course. ${ }^{76} \operatorname{LoE} 5$, SoR D, LoA 8.4 (1.6).

8. If the treatment target is not achieved with the first csDMARD strategy and poor prognostic factors are present, a bDMARD or a tsDMARD should be added. In 2016, this recommendation read as follows: "If the treatment target is not achieved with the first csDMARD strategy, when poor prognostic factors are present, addition of a bDMARD or a tsDMARD should be considered; current practice would be to start a bDMARD." Thus, there are two major changes in the 2019 update. First, the task force revised the preference of bDMARDs over tsDMARDs because of new evidence regarding the successful long-term efficacy and safety of JAKis. ${ }^{77-79}$ Second, it recommended that a bDMARD should be 'added' rather than 'considered'.
Regarding the first change, the task force also agreed that bDMARDs and tsDMARDs have on average similar efficacy and, therefore, no preference can be given to any of these agents for reasons of efficacy. While two studies designed as noninferiority trials have shown statistical superiority of baricitinib or upadacitinib compared with adalimumab (all in combination with MTX), ${ }^{80} 81$ a third study using tofacitinib+MTX did not show such superiority ${ }^{82}$; thus, the overall clinical relevance of small differences in clinical trials was not considered convincing enough for the task force to prefer tsDMARDs over bDMARDs. This conclusion is further supported by recently presented data revealing that filgotinib + MTX met non-inferiority for Disease Activity Score $28<3.2$, but not superiority criteria, when compared with adalimumab, a prespecified endpoint, although superiority was observed for some of the secondary endpoints. ${ }^{83}$ Importantly, in these studies various inflammatory markers, such as swollen joint counts, did not differ among the groups, in line with the hitherto unknown clinical relevance mentioned above.

A third JAKi, peficitinib, has meanwhile been approved in Japan where clinical trials revealed significant efficacy ${ }^{84} 85$; in a global study, efficacy was not similarly apparent, possibly due to high placebo effects. ${ }^{86}$

A fourth JAKi, upadacitinib, has undergone testing in phase III trials in different RA populations as combination and monotherapy, ${ }^{27}$ adding to the documented efficacy of this class of drugs; upadacitinib has meanwhile been approved at $15 \mathrm{mg}$ daily by the FDA of the USA with a variety of warnings added to the prescribing information, including a warning that thromboses have occurred in patients treated with $\mathrm{JAKis}^{87}$; also EMA has given a positive opinion on upadacitinib.

For a fifth JAKi, filgotinib, publication of further phase III trial results is awaited and the drug is currently undergoing regulatory evaluation.

With respect to safety, beyond what was known to the last task force and further corroborated in the course of the current safety SLR such as an increased risk of herpes zoster infections, ${ }^{26}$ a new safety issue, namely VTEs including pulmonary embolism, has emerged for both baricitinib (4 mg daily) ${ }^{88}$ and tofacitinib (at both $5 \mathrm{mg}$ and especially $10 \mathrm{mg}$ twice daily particularly in patients with risks of thromboembolic events and higher age). ${ }^{89}$ These latter data on tofacitinib are derived from an interim analysis of study A3921133 (NCT02092467), an ongoing study that compares tofacitinib at 5 and $10 \mathrm{mg}$ twice daily with TNF inhibition regarding major cardiovascular events and malignancy in patients with RA and at least one cardiovascular risk factor. ${ }^{90}$ Thromboembolic events have also been observed with upadacitinib. ${ }^{9192}$ VTEs are seen especially in patients with a high risk for these events (see safety SLR), such as those with a previous history of thromboembolic events, those with high body mass index, those with hormone replacement therapy and higher age. ${ }^{8893}$ Therefore, JAKi should be used with caution in patients with high risk of TE events. Moreover, currently information regarding this risk is not yet final and further accruing, and it is not understood which mechanisms may drive this risk; this should become a major target of research.

Thus, the decision which drug to prescribe when a patient has failed to reach the treatment target with the first therapeutic strategy and has unfavourable prognostic markers should be based on an aggregate of contraindications, patient preference and costs.

The second change that a bDMARD or tsDMARD should be 'added' rather than 'considered' constitutes a stronger support for combination therapy (item 9) than before. In previous years, the SLRs have revealed evidence of similar efficacy among the 
bDMARDs, ${ }^{23}$ and this obviously includes biosimilars approved by European Medicines Agency (EMA) or US Food and Drug Administration (FDA). ${ }^{27}$

No new studies on the efficacy of csDMARDs after prior failure of MTX (or other csDMARDs) have been performed since the last update, but during the discussions of the last update sufficient evidence was found showing that the benefit of this approach is limited and progression of damage may accrue. ${ }^{94} 95$ Given that the costs of bDMARD and tsDMARD have decreased in many countries since the advent of biosimilars, the task force members felt that this recommendation should be reinforced. Some participants suggested applying a similar recommendation even for patients who do not exhibit poor prognostic factors (item 7), but this suggestion did not find sufficient resonance in the task force. On the other hand, no study has directly compared the benefit of add-on bDMARDs or tsDMARDs vs a second course of csDMARDs (plus GCs) in patients without poor prognostic factors who failed a first course of MTX; this has not even been done for patients with poor prognostic factors. This continues to be part of the research agenda. The new wording was approved by $95 \%$ of the participants. LoE for general efficacy: 1a (regarding its primary use in patients with poor prognostic factors: 5), SoR A (D), LoA 9.3 (1.0).

9. $b D M A R D s$ and tsDMARDs should be combined with a csDMARD; in patients who cannot use csDMARDs as comedication, IL-6 pathway inhibitors and tsDMARDs may have some advantages compared with other bDMARDs (unchanged). The task force reiterated that-in contrast to clinical practice where up to $40 \%$ of patients are on bDMARD monotherapy-combination therapy is advantageous with respect to efficacy compared with monotherapy for all bDMARDs and tsDMARDs and with respect to immunogenicity for all bDMARDs. When MTX is part of such combination therapy, high MTX doses may not be necessary: in combination with TNFi (and presumably other therapies), $10 \mathrm{mg} /$ week may be sufficient ${ }^{9697}$ to increase the efficacy of the bDMARD. Tocilizumab and sarilumab as monotherapy are more efficacious than adalimumab monotherapy and JAKi monotherapy generally also has good clinical efficacy. In light of these observations, the task force discussed if the second part of the sentence should read 'should be preferred' rather than 'may have some advantages', but this proposal did not reach a $75 \%$ majority. LoE 1a, SoR A; LoA 8.9 (1.1).

10. If a bDMARD or tsDMARD has failed, treatment with another bDMARD or a tsDMARD should be considered; if one TNFi therapy has failed, patients may receive an agent with another MOA or a second TNFi. The first part of this recommendation remains unchanged. The second part underwent a slight modification by changing the sequence: the task force now placed 'another MOA' before 'a second TNFi'. This amendment was based on some reports from registry data, observational studies and a randomised controlled trial suggesting that using another MOA leads to better efficacy than a second TNFi. ${ }^{98-100}$ However, these and similar other studies may have had a high risk of bias and, as detailed in the previous SLR, a meta-analysis of randomised controlled trials performed in patients with an IR to TNFis did not reveal differences in efficacy between switching to a second TNFi and using a different drug class, ${ }^{23}$ although these were separate and not head-to-head studies. This recommendation does not only relate to failure of TNFi, but rather to failure of any bDMARD or tsDMARD. While data for the efficacy of TNFi after failure of another TNFi have been available for long. ${ }^{101-103}$ At the time of the SLRs, no data were available regarding studies of (1) IL-6R inhibitors after prior failure of another such compound (eg, sarilumab after failure of tocilizumab), (2) JAKis after failure of another one (eg, baricitinib after IR to tofacitinib or (3) bDMARDs after failure of tsDMARDs. However, since then a recent post-hoc analysis of a clinical trial suggested also some efficacy of sarilumab after failure of tocilizumab ${ }^{104}$ and a study using a TNFi after IR to a JAKi was published, revealing similar overall outcomes as switching from a TNFi to a JAKi. ${ }^{105}$ Needless to say that the term 'second TNFi' does not relate to a biosimilar of the failed compound but to a molecularly different TNFi. Among the task force members, $84 \%$ agreed with the change. The LoE continues to be $1 \mathrm{a}$ for patients who did not sufficiently respond to TNFis (SoR A); JAK inhibition was studied in RCTs after failure of several bDMARDs. ${ }^{91} 106$ LoE 1a, SoR A; LoA 8.9 (1.2).

11. If a patient is in persistent remission after having tapered glucocorticoids, one can consider tapering bDMARDs or tsDMARDs, especially if this treatment is combined with a csDMARD. In this update, the term 'tsDMARD' was now included, based on respective trial data. ${ }^{107}$ Otherwise the recommendation remained unchanged. In the discussions, the task force members reinforced the proposed sequence (stopping GCs first and subsequently, when the treatment target is sustained, reducing bDMARDs or tsDMARDs). With the reiteration of this principle ('persistent remission' recommended before starting drug tapering) which has been introduced already in 2010 and maintained ever since, because no conflicting data became available, the task force explicitly affirmed the requirement of persistent remission before initiation of dose reduction or interval increase of bDMARDs or tsDMARDs. It is important to mention that discontinuation of bDMARDs is frequently associated with flares (increasing with time since discontinuation) and that, therefore, many task force members would have preferred to see tapering just as a dose reduction or interval increase rather than leading to discontinuation; however, the vast majority $(>80 \%)$ of patients who flare can regain a good outcome on reinstitution of the previous treatment. ${ }^{107} 108$

A definition for the term 'persistent' is not available, since no study investigated whether 3, 6 or 12 months of stringent remission is more appropriate for such definition; in some studies, 6 months of remission was used for this purpose, but this needs to be part of the research agenda. Several studies showed a clear correlation of flare risk with failure to achieve 'deep' or 'stringent' remission prior to bDMARD tapering ${ }^{107}{ }^{109-112}$; however, this was not definitely established in a recent systematic literature review because of conflicting study data, ${ }^{113}$ Flares after bDMARD tapering are associated with a progression of joint damage, especially when leading to long-term increase in disease activity, ${ }^{114} 115$ while progression of damage may not be seen with short lived flares. ${ }^{115}$ Importantly, also small increases in joint damage may become significant over years and lead to irreversible disability. ${ }^{115}$

Thus, overall, persistent ACR-EULAR remission is associated with lowest risk of flares and tapering while in LDA (including other, less stringent states previously termed remission) is not recommended because of a higher risk of flares. ${ }^{114}$ Further, tapering may have to be approached particularly carefully in patients who have joint damage, since these patients have a high risk of damage progression on complete withdrawal of bDMARDs, similar to patients with elevated levels of acute phase reactants or residual (low) disease activity, which is not seen on dose reduction. ${ }^{114}$ As an additional discussion point in this respect, it was suggested to consider continuing the bDMARD (or tsDMARDs) while stopping the accompanying csDMARD. However, a recent randomised trial investigating this question yielded no difference in outcomes between these two 
Box 1 Research agenda

1. Do we have enough data to recommend a specific treatment in patients with pre-rheumatoid arthritis (RA) at high risk to develop RA?

2. Is the application of a tumour necrosis factor (TNF) inhibitor after abatacept, tocilizumab, rituximab or a JAK inhibitor (JAKi) has failed, safe and efficacious?

3. How safe and efficacious are abatacept, tocilizumab and rituximab after any of the other non-TNF inhibitor-biological disease modifying antirheumatic drugs (b) DMARDs or a targeted synthetic (ts) DMARD has failed?

4. How safe and efficacious is the use of an interleukin 6 (IL-6) pathway inhibitor if another IL-6 pathway inhibitor/a JAKi has failed?

5. How safe and efficacious is the use of a JAKi after another JAKi has failed?

6. How safe and efficacious is the combination of a JAKi with a bDMARD, such as a TNF inhibitor?

7. Does the risk stratification for bDMARD/tsDMARD initiation based on presence of good or bad prognostic factors as recommended by European League Against Rheumatism translate into improved outcomes for both prognosis groups?

8. Do patients who lack poor prognostic factors benefit as much from a switch or addition of a conventional synthetic (cs) DMARD as from the addition of a bDMARD?

9. Is tapering of bDMARD monotherapy possible?

10. Will randomised controlled trials on tapering of bDMARDs or tsDMARDs designed to following predefined predictors for the maintenance of good outcomes after their withdrawal shows success?

11. How good is patient adherence to a bDMARD or tsDMARD and can non-adherence explain secondary loss of efficacy?

12. How can refractory RA be best defined, and what is the optimal treatment approach?

13. Can we identify new biomarkers to stratify patients and to predict therapeutic response and pending lack of response?

14. Which other factors, for example, lifestyle characteristics or treatment history or allow to make the best possible therapeutic decisions?

15. Do JAKi confer specific safety signals of concern?

16. What are the molecular pathways associated with thromboembolism when using JAKi?

17. Can the identification of disease phenotypes inform tailored therapeutic use?

18. Do the different bDMARDs/tsDMARDs lead to comparable improvements in comorbidities/multimorbidities?

19. Does the concomitant use of glucocorticoids at very low doses (1-3 mg prednisone equivalent) increase therapeutic success without producing unacceptable side effects?

20. Will therapeutic drug monitoring improve disease course and outcome and support decisions about switching within or between drugs?

21. Is leflunomide equivalent to methotrexate as first-line csDMARD therapy?

22. For active patients with RA who have failed multiple drugs, are there combinations that may be more successful such as JAKi with bDMARD?

23. Is secondary loss of efficacy due to non-adherence or a consequence of true loss of efficacy of a given drug and if the latter, what is the reason for this loss of efficacy?

Continued
Box 1 Continued

24. How long should the duration of persistent remission or requirements be before csDMARD can be tapered?

25. Are the Boolean remission criteria sufficiently well-defined?

26. Can taxonomy of RA be improved to guide therapeutic decisions?

strategies ${ }^{116}$; thus for cost and safety reasons, the committee still supports that bDMARD and tsDMARD rather than csDMARDs should be tapered first. Among the participants, 93\% approved this change. LoE 1b, SoR A, LoA 9.2 (1.0).

12. If a patient is in persistent remission, tapering the csDMARD could be considered. While combining recommendations 11 and 12 was discussed, the ultimate decision of the task force was to leave them separate and not change this item. This point relates primarily to two aspects: (1) in patients who have responded well to a csDMARD and did not need a bDMARD or tsDMARD, the csDMARD dose may be reduced in persistent remission and (2) in a patient who was on combination therapy and in whom slow dose reduction or interval increase of a bDMARD or tsDMARD has ultimately resulted in cessation of this added therapy with maintenance of persistent remission, one may consider also reducing the csDMARD dose. However, one needs to bear in mind that RA is regarded a usually incurable disease and that, therefore, a drug that has proven efficacy and is tolerated by the patient should not be stopped. With regards to the question of stopping versus continuing csDMARDs in remission, no new trials have been found in the current SLR, an older trial comparing withdrawal versus continuation of csDMARDs in patients in remission found a significant increase in flare rate and restitution to the situation prior to discontinuation may not be as successful with csDMARDs as with bDMARD or tsDMARD reinstitution, since only half of the patients regained the previous state. ${ }^{117118}$ Dose reduction, however, can be considered. LoE $2 b$, SoR B, LoA 9.0 (1.1).

Figure 1 depicts the algorithm based on the updated recommendations. The figure is an abbreviated version of table 2 and the footnotes explain the definitions used. The research agenda (box 1) is an update of the previous version, of which several questions have been addressed over the last 3 years.

\section{DISCUSSION}

Since the 2016 update, several new drugs have been approved in Europe. These new drugs are all within classes that had already been licensed for use in patients with RA, such as additional bsDMARDs inhibiting TNF; sarilumab, an anti-IL-6 receptor antibody that targets the same molecule as tocilizumab; and tofacitinib and baricitinib, two JAKis of which tofacitinib had already long been used in the USA and other regions of the world. Thus, major changes of these recommendations were not to be expected, but revisiting recommendations with respect to their timeliness is important to ensure that their evidence is maintained or strengthened or, when contradicting data become apparent, that they are amended to reflect the latest knowledge and evidence base.

The 2019 update of these recommendations, therefore, consolidates the previous efforts while adding one overarching principle (item D).

As before, the recommendations are ordered in terms of a sequential treatment strategy from the time point of diagnosis and the requirement to immediately start a DMARD therapy 
(item 1) to the tapering of treatment once a stringent remission has been achieved (items 11, 12). Nine of the specific recommendations were not changed (1-7, 9 and 12). The recommendation to use MTX plus GC as an initial treatment strategy (5 and 6), while unchanged, has been reinforced by the task force; indeed, an abstract presented after the task force meeting revealed that MTX plus GC is non-inferior to three bDMARD MOAs combined with MTX, namely certolizumab (TNF), tocilizumab (IL-6R) and abatacept (costimulation), ${ }^{71}$ confirming and further strengthening the task forces' long-standing recommendation in this respect. This recommendation relates to the initiation of csDMARD therapy and bridging therapy with GC, not to long-term use of GC after the bridging period which may be afflicted with cardiovascular and other risks. ${ }^{34} 119-121$ In patients with early RA who fail MTX by 6 months, addition of bDMARDs/tsDMARDs is associated with a similar overall rate of LDA or remission at 12 months from treatment start as immediately starting a TNFi plus MTX; ${ }^{72}$ it is conceivable that this also pertains to other agents, although such data are currently lacking. Thus, reduced response rates to subsequent therapies are primarily due to long disease duration and failure of several csDMARDs before initiation of a bDMARD or tsDMARD and not primarily a consequence of failing MTX. ${ }^{122}$

The task force maintained its recommendation to stratify patients who failed to attain the treatment target with the first treatment strategy into those with and those without poor prognostic factors. The task force also reiterated its previous decision that bDMARDs and tsDMARDs should primarily be combined with csDMARDs, such as MTX, a decision now strengthened by the new SLR data allowing the LoE to rise from $1 \mathrm{~b}$ to $1 \mathrm{a}$ also for tsDMARDs.

No evidence is available for switches between IL-6 receptor inhibitors or between JAKis. However, the task force assumed that these are similarly efficacious to switches for which direct evidence exists. This assumption was partly confirmed in a recent post hoc analysis of sarilumab in patients with an insufficient response to tocilizumab and trial showing efficacy of a bDMARD after an IR to a tsDMARD. ${ }^{104} 105$

Whereas the first 10 items address therapeutic strategies for patients with active RA from the time of diagnosis to failure of sequential therapies, the last two recommendations deal with patients in whom remission was attained. Tapering of bDMARDs and tsDMARDs should be cautious and only be started when stringent remission, such as based on the ACR-EULAR definitions, is sustained. It should be noted that flares are frequent after withdrawal of bDMARDs and tsDMARDs and increase with time from cessation. There is no evidence supporting withdrawal of csDMARDs before bDMARDs (or tsDMARDs), as also revealed by a recent trial comparing these two strategies. ${ }^{116}$ Thus, maintaining a bDMARD or tsDMARD at a reduced dose or an expanded interval may be prudent.

Overall, the 2019 update reveals that various principles, such as the principle of (early) remission induction by virtue of T2T and the value of GCs and csDMARDs in this trajectory are firmly established. The ongoing development of new bDMARDs and tsDMARDs has allowed for an increasing proportion of patients to attain the treatment target. On the other hand, new bDMARDs and tsDMARDs primarily have access to the affluent markets because of their high price, thereby continuing to leave an unmet need in patients with RA in less affluent countries (most countries of the world) or in less affluent patients in high-income countries (such as in the USA). The task force considers this a challenge to organisations like EULAR, APLAR, PANLAR and ACR. Moreover, it appears that the financial benefits brought by the advent of more affordable bsDMARD to most European Union countries have not been seen in other regions to a nearly similar extent.

While recommendations presented in this update summarise the state of art from an evidence-driven point of view, they will always be aspirational in nature. They reflect 'best practice', provided in an ideal world in which physicians adhere to the principle of assessing the patients regularly and making decisions driven by these assessments. They assume that rheumatologists are aware of the various drugs' safety issues, such as the risk of thromboembolic events on use of JAKi, especially in patients with cardiovascular risk factors, that was recently reported by regulators. ${ }^{5389}$ They also assume patients adhere to the medication selected and prescribed in a shared decision process. In this imaginary world of 'best practice', costs are not a limiting factor. Such aspirational recommendations should be read as an encouragement to all that are involved in improving access to healthcare in less affluent situations.

Aspirational recommendations may have their downsides. They may inadvertently contribute to what is called by some 'the race to the end': the infinite search for ever subtler improvements in efficacy and safety at ever higher expenses and attainable for ever fewer patients. Moreover, overdiagnosis and overtreatment ${ }^{123}$ may add to treatment inefficiency, risks and costs. It is the responsibility of the national and international professional societies to provide sufficient postgraduate education and information on benefits and risks of available drugs, so that appropriate RA treatment is applied and thus not only stays manageable in terms of costs but also becomes attainable to those living in less affluent situations. This is conveyed with the present EULAR recommendations. Another good example of activities is the EULAR initiative to provide recommendations for difficult-to-treat RA, ${ }^{124}$ which will address the question if a once established diagnosis continues to be correct and will point to distinctions between inflammatory and non-inflammatory symptoms when deciding about T2T. In this respect, it is important to note that we are encountering an increasing number of patients who are 'refractory' to treatment or 'difficult to treat', ${ }^{124} 125$ and for whom the current recommendations also apply, provided a correct diagnosis and assessment of ongoing disease activity have been made. A correct diagnosis is key for the correct application of recommendations and appropriate use of medicines, ${ }^{20}$ which in RA means to combat inflammation. However, since refractoriness appears to be associated with treatment delays and high initial inflammatory load, ${ }^{125}$ rapid institution of appropriate treatment strategies once the diagnosis is made (recommendation 1) is of crucial importance.

In summary, the 2019 update of the EULAR recommendations provides rheumatologists, patients, health professionals and other stakeholders with the most recent evidence regarding the management of patients with RA. Adhering to these recommendations, which are based on systematic literature reviews and opinions of experts from around the world, will allow optimal treatment of patients with RA at the beginning of the third decade of this century. Using the many therapeutic options available, the treatment target can be reached in most patients; however, about 20\%-30\% remain refractory to current therapies. ${ }^{125}$ For these, new treatment options, but also better insights into the pathogenesis of RA will be needed. The research agenda points to unresolved questions and enables future task forces to further improve the EULAR recommendations.

As reflected by the current update in comparison with the previous one, for most of the therapeutic aspects of RA, we have reached a steady state of the evidence base for patients 
with established RA, although still some needs remain unmet, ${ }^{126}$ including the need to cure the disease. With the current rate of evidence development, we expect an update of the recommendations to be necessary in about 3-4 years.

\section{Author affiliations}

'Division of Rheumatology, Department of Medicine 3, Medical University of Vienna, Vienna, Austria

${ }^{2}$ Amsterdam University Medical Center, Amsterdam, The Netherlands

${ }^{3}$ Zuyderland Medical Center, Heerlen, The Netherlands

${ }^{4}$ Department of Rheumatology and Clinical Immunology, University Medical Center Utrecht, Utrecht, The Netherlands

${ }^{5}$ Department of Rheumatology and Clinical Immunology, Charité - University Medicine Berlin, Free University and Humboldt University Berlin, Berlin, Germany ${ }^{6}$ Rhumatologie B, Hopital Cochin, 27 rue du Fbg Saint-Jacques, Paris, France ${ }^{7}$ Institute of Infection, Immunity and Inflammation, College of Medical, Veterinary and Life Sciences, University of Glasgow, Glasgow, UK

${ }^{8}$ NOVA Medical School, Universidade Nova de Lisboa, Lisbon, Portugal, and Department of Rheumatology, Leiden University Medical Center, Leiden, The Netherlands

${ }^{9}$ Department of Rheumatology, VU University Medical Center, Amsterdam, The Netherlands

${ }^{10}$ EULAR Patient Research Partner; Department Medical Humanities, Amsterdam University Medical Center, Amsterdam, The Netherlands

${ }^{11}$ Division of Rheumatology, Department of Medicine III, University Medical Center and Faculty of Medicine Carl Gustav Carus, Dresden, Germany

${ }^{12}$ Department of Rheumatology, Karolinska University Hospital, Stockholm, Sweden

${ }^{13}$ Servicio de Reumatologia Hospital Universitario La Paz, Instituto de Investigacion IdiPAZ, Madrid, Spain

${ }^{14}$ Department of Epidemiology and Biostatistics and Amsterdam Rheumatology and Immunology Center, Amsterdam UMC, Vrije Universiteit Amsterdam, Amsterdam, The Netherlands

${ }^{15}$ Department of Rheumatology, Sint Maartenskliniek, Nijmegen, The Netherlands ${ }^{16}$ Division of Musculoskeletal and Dermatological Sciences, University of Manchester; NIHR Manchester Biomedical Research Centre, Manchester University NHS Foundation Trust, Manchester, UK

${ }^{17}$ Department of Clinical Sciences and Community Health, University of Milan, and IRCCS S Matteo Foundation, Pavia, Italy

${ }^{18}$ Centro de Investigación Clínica de Morelia SC, Morelia, Michoacán, Mexico

${ }^{19}$ Department of Development and Regeneration, Skeletal Biology and Engineering Research Center, KU Leuven; Rheumatology, University Hospitals Leuven, Leuven, Belgium

${ }^{20}$ Center of Rheumatic Diseases, University of Medicine and Pharmacy, Bucharest, Romania

${ }^{21}$ Research Laboratory and Division of Clinical Rheumatology, Department of Internal Medicine - University of Genoa, Genoa, Italy

${ }^{22}$ Musculoskeletal Research Unit, NIHR Clinical Research Facility, University Hospital Southampton, Southampton, UK

${ }^{23}$ Department of Patient \& Care and Department of Rheumatology, University of Maastricht, Maastricht, The Netherlands

${ }^{24}$ NIHR Leeds Musculoskeletal Biomedical Research Unit, Leeds Teaching Hospitals NHS Trust and Leeds Institute of Rheumatic and Musculoskeletal Medicine, University of Leeds, Leeds, UK

${ }^{25}$ Division of Rheumatology, University Hospitals of Geneva, Geneva, Switzerland

${ }^{26}$ Sorbonne Université, INSERM, Institut Pierre Louis d'Epidémiologie et de Santé Publique, Paris and Pitié Salpêtrière hospital, AP-HP, Rheumatology Department, Paris, France

${ }^{27}$ Strasbourg University Hospital and University of Strasbourg, CNRS, Institut de Biologie Moléculaire et Cellulaire, Immunopathologie, et Chimie Thérapeutique, Strasbourg, France

${ }^{28}$ Copenhagen Center for Arthritis Research, Center for Rheumatology and Spine Diseases, Rigshospitalet and Department of Clinical Medicine, Faculty of Health and Medical Sciences, University of Copenhagen, Copenhagen, Denmark

${ }^{29}$ Department of Rheumatology, Leiden University Medical Center, Leiden, The Netherlands

${ }^{30}$ European League Against Rheumatism, Zurich, Switzerland

${ }^{31}$ Cyprus League against Rheumatism, Nikosia, Cyprus

${ }^{32}$ Department of Rheumatology and Immunology, Beijing University People's Hospital, Beijing, China

${ }^{33}$ Université Paris-Sud, AP-HP, Université Paris-Saclay, Le Kremlin Bicêtre, France

${ }^{34}$ Department of Rheumatology and Clinical Immunology, Campus Kerckhoff, JustusLiebig University Giessen, Bad Nauheim, Germany

${ }^{35}$ Organización Médica de Investigación, Buenos Aires, Argentina

${ }^{36}$ Serviço de Reumatologia, Centro Hospitalar e Universitário de Coimbra Praceta

Mota Pinto, and Coimbra Institute for Clinical and Biomedical Research (i-CRB),

Faculty of Medicine of Coimbra, Coimbra, Portugal
${ }^{37}$ National Institute of Rheumatology \& Physiology, Semmelweis University, Budapest, Hungary

${ }^{38}$ University of Western Ontario, Schulich School of Medicine \& Dentistry, Department of Medicine, London, Ontario, Canada

${ }^{39}$ Klinik für Rheumatologie, Kantonsspital St Gallen, St Gallen, Switzerland

${ }^{40}$ UMR 1027, Inserm, Université Paul Sabatier Toulouse III, Toulouse, France

${ }^{41}$ Department of Medicine, Division of Rheumatology, University of Alabama at Birmingham, Brmingham, Alabama, USA

${ }^{42}$ Programme Area Epidemiology, Deutsches Rheumaforschungszentrum Berlin, Berlin, Germany

${ }^{43}$ Keio University School of Medicine, Keio University Hospital, Tokyo, Japan

${ }^{44}$ Department of Psychology, Health and Technology, University of Twente, Enschede,

The Netherlands

Correction notice This article has been corrected since it published Online First. A typographical error in the footnote of table 2 has been corrected.

Twitter Mario Humberto Cardiel @cardielmh

Acknowledgements The task force is grateful to EULAR for funding this activity under project number CLI111.

Contributors The paper was drafted by JSS and RBML and all authors contributed with specific comments and revisions to the paper.

Funding This study was funded by European League Against Rheumatism (grant number:CLI111).

Competing interests DA: grants from Abbvie, Novartis, Roche and honoraria from Abbvie, Amgen, Celgene, Lilly, Medac, Merck, Novartis, Pfizer, Roche, Sandoz, Sanofi/Genzyme; MA: honoraria from AbbVie, Astra Zeneca, BMS, Boehringer Ingelheim, Chugai, HEXAL, Lilly, MSD, Novartis, Pfizer, Roche, Sanofi, UCB; JA: grants from Abbvie, BMS, Lilly, Merck, Pfizer, Roche, Samsung Bioepis, UCB; AB: grants from Pfizer, Bristol-Myers Squibb and honoraria from Pfizer, Roche, AbbVie, Bristol-Myers Squibb, UCB, MSD, Novartis, Sanofi, Biogen, Sandoz, Celltrion, Nordic, Gilead; JWJB: honoraria from Lilly, Roche, Sanofi; MB: honoraria from BMS, Teva, Novartis, Pfizer, GSK; AdB: grants from Abbvie, Biogen, Celltrion and honoraria from Abbvie, Biogen, Boehringer-Ingelheim, Celgene, Fresenius, MSD, Roche.MHB has received grants from Pfizer, Roche and UCB and consulting fees from Abbvie, Eli-Lilly, Merck.Serono, Pfizer, Sandoz, Sanofi; GB: grants from Abbvie, Pfizer, Sanofi, UCB and honoraria from Abbvie, Celgene, Gilead, Lilly, MSD, Novartis, Pfizer, Sanofi, Roche. FB: grants from Abbvie, BMS, Horizon, Medac, Pfizer, Roche, Lilly, Sanofi and honoraria from Abbvie, Galapagos, Horizon, Medac, Pfizer, Roche, Sanofi, Janssen, BMS, MSD, Lilly; RC: honoraria from Abbvie, BMS, Celgene, Celltrion, Gilead, Janssen, Lilly MSD, Mundipharma, Novartis-Sandoz, Pfizer, Roche, Sanofi and UCB; MC; honoraria from Abbvie, Astellas, BMS, Lilly, Pfizer and Roche; DDC: no conflict; CC: honoraria from AbbVie, Accord Healthcare, Alfasigma, Berlin Chemie, Egis, Eli Lilly, Ewopharma, Genesis, MSD, Mylan, Novartis, Pfizer, Roche, Sandoz, UCB; MD: grants from Pfizer, Abbvie, UCB, Janssen, Novartis and honoraria from Pfizer, Abbvie, UCB, Janssen, MSD, Novartis, BMS, Celgene, Biogen, Sandoz; CJE: grants from Abbvie, Biogen and honoraria from Abbvie, BMS, Biogen Celgene, Fresenius, Gilead, Janssen, Lilly, Mundipharma, Pfizer, MSD, Novartis, Roche, Samsung, Sanofi, UCB; PE: grants from AbbVie, Novartis, Samsung, Lilly and honoraria from AbbVie, Novartis, BMS, Gilead, Samsung, Lilly; AF: grants from BMS, Pfizer and honoraria from AB2 BIO, Abbvie, BMS, Lilly, MSD, Pfizer, Roche, Sanofi; LG: grants from Abbvie, BMS, Lilly, UCB and honoraria from Abbvie, Biogen, Celgene, Janssen, Lilly, Novartis, Pfizer, Sanofi-Aventis, UCB; J-EG: grants from BMS, Pfizer and honoraria from Abbvie, BMS, Lilly, Sanofi-Genzyme, Roche, UCB; MLH: grants from Abbvie, Biogen, BMS, Celltrion, MSD, Novartis, Orion, Pfizer, Samsung, UCB; TH: grants from Lilly, Merck, UCB, BMS, Janssen, Pfizer, SanofiAventis, Galapagos, Boeringher and honoraria from Abblynx, BMS, Janssen, Pfizer, Sanofi-Aventis, Crescendo Bioscience, Galapagos, Lilly; AK: honoraria from BMS, Pfizer, Celgene, MSD; MK: no conflicts of interest; RBML: honoraria from AbbVie, BMS, Celgene, Eli-Lilly, Jansen Pharmaceuticals, Galapagos, Novartis, MSD, Pfizer, UCB and Director of Rheumatology Consultancy BV; XM: honoraria from BMS, Gilead, Pfizer, Samsung, UCB; IBM: grants from Astra Zeneca, UCB, BMS, Janssen, GSK, Compugen, Boehringer, Celgene and honoraria from Abbvie, BMS, Janssen, Novartis, UCB, Astra Zeneca, Celgene, Causeway, Lilly, Leo, Novimmune; EM: grants from Pfizer, Lilly, BMS, AbbVie, GSK, Astra and honoraria from Pfizer, BMS, Roche, Lilly, AbbVie, Gemma, Sanofi; TWJH: grants from Eli Lilly, Merck, UCB, BMS, Janssen, Pfizer, Sanofi-Aventis, Galapagos, Boehringer and honoraria from Abblynx, Abbvie, BMS, Boehringer, Crescendo-Bioscience, Epirus, Galapagos, Janssen, Lilly, Merck, Novartis, Nycomed, Pfizer, Roche, Sanofi-Aventis, Takeda, UCB; ZL: no conflicts of interest; UM-L: honoraria from Abbvie, BMS, MSD, Chugai, Roche, Pfizer, Sanofi, Boehringer, Actelion, Medac, Lilly; GP: no conflicts of interest; JP: grants from BMS, Merck, UCB and honoraria from AbbVie, Actelion, Amgen, BMS, Bayer, GSK, Lilly, Merck, Novartis, Pfizer, Roche, Sandoz, Sanofi, UCB; AR-R: honoraria from Abbvie, Chugai, BMS, Sanofi, Roche, Lilly, Janssen, Novartis, Celgene, MSD, UCB; AR-W: grants from Pfizer, Abbvie and honoraria from Abbvie, Amgen, BMS, Janssen, Lilly, Medac, Nordic Pharma, Novartis, Pfizer, Roche-Chugai, Sanofi, UCB; KS: grants from Amgen, Ironwood/AstraZeneca, Horizon, SOBI, Takeda and honoraria from 
AbbVie, Amgen, Ironwood/AstraZeneca, Bayer, Gilead, Horizon, Kowa, Radius, Roche/Genentech, SOBI, Takeda, Teijin; MSV: no conflicts of interest. AS: honoraria from Novartis; JSS: grants from Abbvie, AstraZeneca, Janssen, Lilly, Novartis, Roche and honoraria from Abbvie, Amgen, AstraZeneca, Astro, BMS, Celgene, Celltrion, Chugai, Gilead, ILTOO, Janssen, Lilly, MSD, Novartis-Sandoz, Pfizer, Roche, Samsung, Sanofi, UCB; AS: grants from AbbVie, Bristol-Myers Squibb, Celltrion, Hexal AG Lilly, MSD Sharp \& Dome, Pfizer, Roche, Samsung Bioepis, Sanofi-Aventis, UCB and honoraria from AbbVie, BMS, MSD, Pfizer, Roche; TT: grants from AbbVie, Asahikasei, Astellas, AYUMI, Chugai, Daiichi Sankyo, Eisai, Mitsubishi Tanabe, Nipponkayaku, Novartis, Pfizer, Takeda and honoraria from AbbVie, Astellas, Astra Zeneca, BMS, Chugai, Diaichi Sankyo, Eisai, Eli Lilly, GlaxoSmithKline, Janssen, Mitsubishi Tanabe, Nipponkayaku, Novartis, Pfizer, Sanofi, Teijin, Taiho Pharmaceutical, Taisho Pharmaceutical, Takeda, UCB; DvdH: grants from UCB and honoraria from AbbVie, Amgen, Astellas, AstraZeneca, BMS, Boehringer Ingelheim, Celgene, Daiichi, Eli-Lilly, Galapagos, Gilead, GlaxoSmithKline, Janssen, Merck, Novartis, Pfizer, Regeneron, Roche, Sanofi, Takeda, UCB and Director Imaging Rheumatology BV; YvE-H: honoraria from Celgene; RFvV: grants from BMS, GSK, Lilly, UCB and honoraria from AbbVie, AstraZeneca, Biotest, BMS, Celgene, GSK, Janssen, Lilly, Novartis, Pfizer, Roche, UCB; RW: grants from Roche, BMS and honoraria from Celltrion, GalapagosGilead; MdW: honoraria from 'Stichting Tools', Janssen-Cilag.

Patient consent for publication Not required.

Provenance and peer review Not commissioned; externally peer reviewed.

\section{ORCID iDs}

Josef S Smolen http://orcid.org/0000-0002-4302-8877

Andreas Kerschbaumer http://orcid.org/0000-0002-6685-8873

Alexandre Sepriano http://orcid.org/0000-0003-1954-0229

Maarten de Wit http://orcid.org/0000-0002-8428-6354

Martin Aringer http://orcid.org/0000-0003-4471-8375

Maya H Buch http://orcid.org/0000-0002-8962-5642

Maurizio Cutolo http://orcid.org/0000-0002-5396-0932

Yvonne van Eijk-Hustings http://orcid.org/0000-0002-2325-8114

Paul Emery http://orcid.org/0000-0002-7429-8482

Laure Gossec http://orcid.org/0000-0002-4528-310X

Tom W J Huizinga http://orcid.org/0000-0001-7033-7520

Jose A P da Silva http://orcid.org/0000-0002-2782-6780

Janet E Pope http://orcid.org/0000-0003-1479-5302

Andrea Rubbert-Roth http://orcid.org/0000-0002-9016-2833

Désirée van der Heijde http://orcid.org/0000-0002-5781-158X

\section{REFERENCES}

1 Smolen JS, Landewé R, Breedveld FC, et al. EULAR recommendations for the management of rheumatoid arthritis with synthetic and biological disease-modifying antirheumatic drugs. Ann Rheum Dis 2010;69:964-75.

2 Aletaha D, Neogi T, Silman AJ, et al. 2010 rheumatoid arthritis classification criteria: an American College of Rheumatology/European League against rheumatism collaborative initiative. Arthritis Rheum 2010;62:2569-81.

3 Felson DT, Smolen JS, Wells G, et al. American College of Rheumatology/European League against rheumatism provisional definition of remission in rheumatoid arthritis for clinical trials. Ann Rheum Dis 2011;70:404-13.

4 Klarenbeek NB, Güler-Yüksel M, van der Kooij SM, et al. The impact of four dynamic, goal-steered treatment strategies on the 5-year outcomes of rheumatoid arthritis patients in the best study. Ann Rheum Dis 2011;70:1039-46.

5 Smolen JS, Breedveld FC, Burmester GR, et al. Treating rheumatoid arthritis to target: 2014 update of the recommendations of an international Task force. Ann Rheum Dis 2016;75:3-15.

6 Aletaha D, Smolen JS. Diagnosis and management of rheumatoid arthritis. JAMA 2018;320:1360-72

7 Burmester GR, Bijlsma JWJ, Cutolo M, et al. Managing rheumatic and musculoskeletal diseases - past, present and future. Nat Rev Rheumatol 2017;13:443-8.

8 Smolen JS, Landewé R, Breedveld FC, et al. EULAR recommendations for the management of rheumatoid arthritis with synthetic and biological disease-modifying antirheumatic drugs: 2013 update. Ann Rheum Dis 2014;73:492-509.

9 Smolen JS, Landewé R, Bij|sma J, et al. EULAR recommendations for the management of rheumatoid arthritis with synthetic and biological disease-modifying antirheumatic drugs: 2016 update. Ann Rheum Dis 2017;76:960-77.

10 Singh JA, Saag KG, Bridges SL, et al. 2015 American College of rheumatology guideline for the treatment of rheumatoid arthritis. Arthritis Care Res 2016;68:1-25.

11 Lau CS, Chia F, Harrison A, et al. APLAR rheumatoid arthritis treatment recommendations. Int J Rheum Dis 2015;18:685-713.

12 Brenol CV, Nava JIG, Soriano ER. Proper management of rheumatoid arthritis in Latin America. what the guidelines say? Clin Rheumatol 2015;34:51-5.

13 Putrik P, Ramiro S, Kvien TK, et al. Inequities in access to biologic and synthetic DMARDs across 46 European countries. Ann Rheum Dis 2014;73:198-206.
14 Bergstra SA, Branco JC, Vega-Morales D, et al. Inequity in access to bDMARD care and how it influences disease outcomes across countries worldwide: results from the METEOR-registry. Ann Rheum Dis 2018;77:1413-20.

15 Putrik P, Ramiro S, Keszei AP, et al. Lower education and living in countries with lower wealth are associated with higher disease activity in rheumatoid arthritis: results from the multinational COMORA study. Ann Rheum Dis 2016;75:540-6.

16 Kay J, Schoels MM, Dörner T, et al. Consensus-based recommendations for the use of biosimilars to treat rheumatological diseases. Ann Rheum Dis 2018;77:165-74.

17 Putrik P, Ramiro S, Kvien TK, et al. Variations in criteria regulating treatment with reimbursed biologic DMARDs across European countries. are differences related to country's wealth? Ann Rheum Dis 2014;73:2010-21.

18 Stoffer MA, Smolen JS, Woolf A, et al. Development of patient-centred standards of care for rheumatoid arthritis in Europe: the eumusc.net project. Ann Rheum Dis 2014;73:902-5.

19 van der Heijde D, Aletaha D, Carmona L, et al. 2014 update of the EULAR standardised operating procedures for EULAR-endorsed recommendations. Ann Rheum Dis 2015;74:8-13.

20 Holloway K, van Dijk L. The world medicines situation 2011. rational use of medicines. WHO/EMP/MIE/2011.2.2. Geneva:World Health Organzization, 2011.

21 Brouwers MC, Kho ME, Browman GP, et al. Agree II: advancing Guideline development, reporting and evaluation in health care. Can Med Assoc $J$ 2010;182:E839-42.

22 Ramiro S, Sepriano A, Chatzidionysiou K, et al. Safety of synthetic and biological DMARDs: a systematic literature review Informing the 2016 update of the EULAR recommendations for management of rheumatoid arthritis. Ann Rheum Dis 2017:76:1101-36.

23 Nam JL, Takase-Minegishi K, Ramiro S, et al. Efficacy of biological disease-modifying antirheumatic drugs: a systematic literature review Informing the 2016 update of the EULAR recommendations for the management of rheumatoid arthritis. Ann Rheum Dis 2017;76:1113-36.

24 Chatzidionysiou K, Emamikia S, Nam J, et al. Efficacy of glucocorticoids, conventional and targeted synthetic disease-modifying antirheumatic drugs: a systematic literature review Informing the 2016 update of the EULAR recommendations for the management of rheumatoid arthritis. Ann Rheum Dis 2017:76:1102-7.

25 Guyatt GH, Oxman AD, Kunz R, et al. Incorporating considerations of resources use into grading recommendations. BMJ 2008;336:1170-3.

26 Sepriano A, Kerschbaumer A, Smolen JS, et al. Safety of synthetic and biological DMARDs: a systematic literature review Informing the 2019 update of the EULAR recommendations for the management of rheumatoid arthritis. Ann Rheum Dis 2020:79:747-57.

27 Kerschbaumer A, Sepriano A, Smolen JS, et al. Efficacy of pharmacological treatment in rheumatoid arthritis: a systematic literature research Informing the 2019 update of the EULAR recommendations for management of rheumatoid arthritis. Ann Rheum Dis 2020;79:731-46.

28 OCEBM Levels of Evidence Working Group. Oxford centre for evidence-based medicine. The Oxford 2011 Levels of Evidence, 2011.

29 Götestam Skorpen C, Hoeltzenbein M, Tincani A, et al. The EULAR points to consider for use of antirheumatic drugs before pregnancy, and during pregnancy and lactation. Ann Rheum Dis 2016:75:795-810.

30 Peters MJL, Symmons DPM, McCarey D, et al. EULAR evidence-based recommendations for cardiovascular risk management in patients with rheumatoid arthritis and other forms of inflammatory arthritis. Ann Rheum Dis 2010;69:325-31

31 van der Goes MC, Jacobs JWG, Boers M, et al. Monitoring adverse events of lowdose glucocorticoid therapy: EULAR recommendations for clinical trials and daily practice. Ann Rheum Dis 2010;69:1913-9.

32 Hoes JN, Jacobs JWG, Boers M, et al. EULAR evidence-based recommendations on the management of systemic glucocorticoid therapy in rheumatic diseases. Ann Rheum Dis 2007;66:1560-7.

33 van Assen S, Agmon-Levin N, Elkayam 0, et al. EULAR recommendations for vaccination in adult patients with autoimmune inflammatory rheumatic diseases. Ann Rheum Dis 2011;70:414-22.

34 Strehl C, Bijlsma JWJ, de Wit M, et al. Defining conditions where long-term glucocorticoid treatment has an acceptably low level of harm to facilitate implementation of existing recommendations: viewpoints from an EULAR Task force. Ann Rheum Dis 2016;75:952-7.

35 Baillet A, Gossec L, Carmona L, et al. Points to consider for reporting, screening for and preventing selected comorbidities in chronic inflammatory rheumatic diseases in daily practice: a EULAR initiative. Ann Rheum Dis 2016;75:965-73.

36 Strangfeld A, Hierse F, Rau R, Pattloch D, Herzer P, et al. Risk of incident or recurrent malignancies among patients with rheumatoid arthritis exposed to biologic therapy in the German biologics register RABBIT. Arthritis Res Ther 2010;12:R5

37 Furst DE, Keystone EC, So AK, et al. Updated consensus statement on biological agents for the treatment of rheumatic diseases, 2012. Ann Rheum Dis 2013;72:ii2-34

38 Buch MH, Smolen JS, Betteridge N, et al. Updated consensus statement on the use of rituximab in patients with rheumatoid arthritis. Ann Rheum Dis 2011;70:909-20. 
39 Pereira R, Lago P, Faria R, et al. Safety of anti-TNF therapies in immune-mediated inflammatory diseases: focus on infections and malignancy. Drug Dev Res 2015;76:419-27.

40 Smolen JS, Schoels MM, Nishimoto N, et al. Consensus statement on blocking the effects of interleukin- 6 and in particular by interleukin- 6 receptor inhibition in rheumatoid arthritis and other inflammatory conditions. Ann Rheum Dis 2013;72:482-92.

41 Zink A, Manger B, Kaufmann J, et al. Evaluation of the Rabbit risk score for serious infections. Ann Rheum Dis 2014;73:1673-6.

42 Strangfeld A, Richter A, Siegmund B, et al. Risk for lower intestinal perforations in patients with rheumatoid arthritis treated with tocilizumab in comparison to treatment with other biologic or conventional synthetic DMARDs. Ann Rheum Dis 2017;76:504-10.

43 Strangfeld A, Eveslage M, Schneider M, et al. Treatment benefit or survival of the fittest: what drives the time-dependent decrease in serious infection rates under TNF inhibition and what does this imply for the individual patient? Ann Rheum Dis 2011;70:1914-20.

44 Jani M, Barton A, Hyrich K. Prediction of infection risk in rheumatoid arthritis patients treated with biologics: are we any closer to risk stratification? Curr Opin Rheumatol 2019;31:285-92.

45 Smolen JS, van der Heijde D, Machold KP, et al. Proposal for a new nomenclature of disease-modifying antirheumatic drugs: Table 1. Ann Rheum Dis 2014;73:3-5.

46 Vastesaeger $\mathrm{N}, \mathrm{Xu}$ S, Aletaha $\mathrm{D}$, et al. A pilot risk model for the prediction of rapid radiographic progression in rheumatoid arthritis. Rheumatology 2009;48:1114-21.

47 Visser K, Goekoop-Ruiterman YPM, de Vries-Bouwstra JK, et al. A matrix risk model for the prediction of rapid radiographic progression in patients with rheumatoid arthritis receiving different dynamic treatment strategies: post hoc analyses from the best study. Ann Rheum Dis 2010;69:1333-7.

48 Combe B, Landewe R, Daien Cl, et al. 2016 update of the EULAR recommendations for the management of early arthritis. Ann Rheum Dis 2017;76:948-59.

49 Taibanguay N, Chaiamnuay S, Asavatanabodee P, et al. Effect of patient education on medication adherence of patients with rheumatoid arthritis: a randomized controlled trial. Patient Prefer Adherence 2019;13:119-29.

50 Solomon DH, Lu B, Yu Z, et al. Benefits and sustainability of a learning collaborative for implementation of Treat-to-Target in rheumatoid arthritis: results of a clusterrandomized controlled phase II clinical trial. Arthritis Care Res 2018;70:1551-6.

51 Navarro-Compán V, Smolen JS, Huizinga TWJ, et al. Quality indicators in rheumatoid arthritis: results from the Meteor database. Rheumatology 2015;54:1630-9.

52 Scotti L, Franchi M, Marchesoni A, et al. Prevalence and incidence of psoriatic arthritis: a systematic review and meta-analysis. Semin Arthritis Rheum 2018:48:28-34.

53 Verden A, Dimbil M, Kyle R, et al. Analysis of spontaneous Postmarket case reports submitted to the FDA regarding thromboembolic adverse events and JAK inhibitors. Drug Saf 2018;41:357-61.

54 Widdifield J, Bernatsky S, Paterson JM, et al. Quality care in seniors with new-onset rheumatoid arthritis: a Canadian perspective. Arthritis Care Res 2011;63:53-7.

55 Memel DS, Somerset M. General practitioner and specialist care: the perceptions of people with rheumatoid arthritis. Primary Health Care Research Development 2003:4:29-37.

56 Robinson PC, Taylor WJ. Time to treatment in rheumatoid arthritis: factors associated with time to treatment initiation and urgent triage assessment of general practitioner referrals. J Clin Rheumatol 2010;16:267-73.

57 Kyburz D, Gabay C, Michel BA, et al. The long-term impact of early treatment of rheumatoid arthritis on radiographic progression: a population-based cohort study. Rheumatology 2011;50:1106-10.

58 Feldman DE, Bernatsky S, Houde M, et al. Early consultation with a rheumatologist for RA: does it reduce subsequent use of orthopaedic surgery? Rheumatology 2013;52:452-9.

59 Aletaha D, Stamm T, Kapral T, et al. Survival and effectiveness of leflunomide compared with methotrexate and sulfasalazine in rheumatoid arthritis: a matched observational study. Ann Rheum Dis 2003:62:944-51.

60 Frisell T, Askling J, Dehlin M. Comment on: comparative effectiveness of abatacept, rituximab, tocilizumab and TNFi biologics in RA: results from the nationwide Swedish register: reply. Rheumatology 2019;58:1510-1.

61 Smolen JS, Aletaha D. Rheumatoid arthritis therapy reappraisal: strategies, opportunities and challenges. Nat Rev Rheumatol 2015;11:276-89.

62 Dörner T, Strand V, Cornes P, et al. The changing landscape of biosimilars in rheumatology. Ann Rheum Dis 2016;75:974-82.

63 Aletaha D, Alasti F, Smolen JS. Optimisation of a treat-to-target approach in rheumatoid arthritis: strategies for the 3-month time point. Ann Rheum Dis 2016;75:1479-85.

64 van der Heijde D, Keystone EC, Curtis JR, et al. Timing and magnitude of initial change in disease activity score 28 predicts the likelihood of achieving low disease activity at 1 year in rheumatoid arthritis patients treated with certolizumab pegol: a post-hoc analysis of the rapid 1 trial. J Rheumatol 2012;39:1326-33.

65 Smolen JS, Aletaha D, Gruben D, et al. Brief report: remission rates with tofacitinib treatment in rheumatoid arthritis: a comparison of various remission criteria. Arthritis Rheumatol 2017;69:728-34.
66 Smolen JS, Aletaha D. Interleukin-6 receptor inhibition with tocilizumab and attainment of disease remission in rheumatoid arthritis: the role of acute-phase reactants. Arthritis Rheum 2011;63:43-52.

67 Gaujoux-Viala C, Rincheval N, Dougados M, et al. Optimal methotrexate dose is associated with better clinical outcomes than non-optimal dose in daily practice: results from the ESPOIR early arthritis cohort. Ann Rheum Dis 2017:76:2054-60.

68 Visser K, van der Heijde D. Optimal dosage and route of administration of methotrexate in rheumatoid arthritis: a systematic review of the literature. Ann Rheum Dis 2009:68:1094-9.

69 Kameda H, Fujii T, Nakajima A, et al. Japan College of rheumatology guideline for the use of methotrexate in patients with rheumatoid arthritis. Mod Rheumatol 2019;29:31-40

70 Nam JL, Villeneuve E, Hensor EMA, et al. Remission induction comparing infliximab and high-dose intravenous steroid, followed by treat-to-target: a double-blind, randomised, controlled trial in new-onset, treatment-naive, rheumatoid arthritis (the idea study). Ann Rheum Dis 2014;73:75-85.

71 Lund Hetland M, Haavardsholm EA, Rudin A, et al. A multicenter randomized study in early rheumatoid arthritis to compare active conventional therapy versus three biological treatments: 24 week efficacy and safety results of the NORD-STAR trial. Arthritis Rheumatol 2019;71:5237-40

72 Kavanaugh A, van Vollenhoven RF, Fleischmann R, et al. Testing treat-to-target outcomes with initial methotrexate monotherapy compared with initial tumour necrosis factor inhibitor (adalimumab) plus methotrexate in early rheumatoid arthritis. Ann Rheum Dis 2018:77:289-92.

73 Van Der Heijde DFM, Van Riel PCM, Nuver-Zwart I, et al. Sulphasalazine versus hydroxychloroquine in rheumatoid arthritis: 3-year follow-up. The Lancet 1990;335:539.

74 Goekoop-Ruiterman YPMet al. Comparison of treatment strategies in early rheumatoid arthritis. Ann Intern Med 2007;146:406-15.

75 Verschueren P, De Cock D, Corluy L, et al. Effectiveness of methotrexate with step-down glucocorticoid remission induction (cobra slim) versus other intensive treatment strategies for early rheumatoid arthritis in a treat-to-target approach: 1-year results of CareRA, a randomised pragmatic open-label superiority trial. Ann Rheum Dis 2017;76:511-20

76 O'Dell JR, Mikuls TR, Taylor TH, et al. Therapies for active rheumatoid arthritis after methotrexate failure. N Engl J Med 2013;369:307-18.

77 Wollenhaupt J, Lee E-B, Curtis JR, et al. Safety and efficacy of tofacitinib for up to 9.5 years in the treatment of rheumatoid arthritis: final results of a global, openlabel, long-term extension study. Arthritis Res Ther 2019:21:89.

78 Keystone EC, Genovese MC, Schlichting DE, et al. Safety and efficacy of Baricitinib through 128 weeks in an open-label, longterm extension study in patients with rheumatoid arthritis. J Rheumatol 2018:45:14-21.

79 Taylor PC, Weinblatt ME, Burmester GR, et al. Cardiovascular safety during treatment with Baricitinib in rheumatoid arthritis. Arthritis Rheumatol 2019:71:1042-55.

80 Taylor PC, Keystone EC, van der Heijde D, et al. Baricitinib versus placebo or adalimumab in rheumatoid arthritis. N Engl J Med 2017:376:652-62.

81 Fleischmann R, Pangan AL, Song In-Ho, et al. Upadacitinib Versus Placebo or Adalimumab in Patients With Rheumatoid Arthritis and an Inadequate Response to Methotrexate: Results of a Phase III, Double-Blind, Randomized Controlled Trial. Arthritis Rheumatol 2019;71:1788-800.

82 Fleischmann R, Mysler E, Hall S, et al. Efficacy and safety of tofacitinib monotherapy, tofacitinib with methotrexate, and adalimumab with methotrexate in patients with rheumatoid arthritis (oral strategy): a phase 3b/4, double-blind, head-to-head, randomised controlled trial. Lancet 2017;390:457-68.

83 Combe B, Kivitz A, Tanaka Y, et al. Efficacy and safety of filgotinib for patients with rheumatoid arthritis with inadequate response to methotrexate:finch1 primary outcome results. Ann Rheum Dis 2019:78:77-8.

84 Tanaka Y, Takeuchi T, Tanaka S, et al. Efficacy and safety of peficitinib (ASP015K) in patients with rheumatoid arthritis and an inadequate response to conventional DMARDs: a randomised, double-blind, placebo-controlled phase III trial (RAJ3). Ann Rheum Dis 2019:78:1320-32.

85 Takeuchi T, Tanaka Y, Tanaka S, et al. Efficacy and safety of peficitinib (ASP015K) in patients with rheumatoid arthritis and an inadequate response to methotrexate: results of a phase III randomised, double-blind, placebo-controlled trial (RAJ4) in Japan. Ann Rheum Dis 2019;78:1305-19.

86 Genovese MC, Greenwald M, Codding C, et al. Peficitinib, a JAK inhibitor, in combination with limited conventional synthetic disease-modifying antirheumatic drugs in the treatment of moderate-to-severe rheumatoid arthritis. Arthritis \& Rheumatology 2017;69:932-42.

87 RINVOQ (upadacitinib). Highlights of prescribing information, 2019. Available: https://www accessdata fda gov/drugsatfda_docs/label/2019/211675s000lbl pdf [Accessed 17 Aug 2019].

88 US Food and Drug Administration. Center for Drug Evaluation and Research. Statistical Review - Clinical Studies - Olumiant (baricitinib), 2019. Available: https://www accessdata fda gov/drugsatfda_docs/ nda/2018/2079240rig1s000StatR pdf

89 European Medicines Agency (EMA). Xeljanz to be used with caution for all patients at high risk of blood clots (EMA/584781/2019), 2019. Available: https://www ema 
europa eu/en/documents/referral/xeljanz-article-20-procedure-xeljanz-be-usedcaution-all-patients-high-risk-blood-clots_en pdf

90 Pfizer. Safety study of tofacitinib versus tumor necrosis factor (TNF) inhibitor in subjects with rheumatoid arthritis, 2019. Available: https://clinicaltrials.gov/ct2/ show/NCT02092467?term=study+A3921133\&draw=1\&rank=1 [Accessed 13 Dec 2019].

91 Genovese MC, Fleischmann R, Combe B, et al. Safety and efficacy of upadacitinib in patients with active rheumatoid arthritis refractory to biologic disease-modifying anti-rheumatic drugs (SELECT-BEYOND): a double-blind, randomised controlled phase 3 trial. Lancet 2018;391:2513-24.

92 Smolen JS, Pangan AL, Emery P, et al. Upadacitinib as monotherapy in patients with active rheumatoid arthritis and inadequate response to methotrexate (SELECTMONOTHERAPY): a randomised, placebo-controlled, double-blind phase 3 study. Lancet 2019;393:2303-11.

93 European Medicines Agency. Increased risk of blood clots in lungs and death with higher dose of Xeljanz (tofacitinib) for rheumatoid arthritis, 2019. Available: https:// www ema europa eu/en/news/increased-risk-blood-clots-lungs-death-higher-dosexeljanz-tofacitinib-rheumatoid-arthritis

94 Goekoop-Ruiterman YPM, de Vries-Bouwstra JK, Allaart CF, et al. Clinical and radiographic outcomes of four different treatment strategies in patients with early rheumatoid arthritis (the best study): a randomized, controlled trial. Arthritis Rheum 2005;52:3381-90.

95 Kiely $\mathrm{P}$, Walsh D, Williams $\mathrm{R}$, et al. Outcome in rheumatoid arthritis patients with continued conventional therapy for moderate disease activity--the early RA network (ERAN). Rheumatology 2011;50:926-31.

96 Maini RN, Breedveld FC, Kalden JR, et al. Therapeutic efficacy of multiple intravenous infusions of anti-tumor necrosis factor ? monoclonal antibody combined with low-dose weekly methotrexate in rheumatoid arthritis. Arthritis \& Rheumatism 1998:41:1552-63.

97 Burmester G-R, Kivitz AJ, Kupper H, et al. Efficacy and safety of ascending methotrexate dose in combination with adalimumab: the randomised concerto trial. Ann Rheum Dis 2015;74:1037-44.

98 Emery P, Gottenberg JE, Rubbert-Roth A, et al. Rituximab versus an alternative TNF inhibitor in patients with rheumatoid arthritis who failed to respond to a single previous TNF inhibitor: SWITCH-RA, a global, observational, comparative effectiveness study. Ann Rheum Dis 2015;74:979-84.

99 Gottenberg J-E, Brocq O, Perdriger A, et al. Non-TNF-Targeted biologic vs a second anti-TNF drug to treat rheumatoid arthritis in patients with insufficient response to a first anti-TNF drug. JAMA 2016;316:1172-80.

100 Gottenberg J-E, Morel J, Perrodeau E, et al. Comparative effectiveness of rituximab, abatacept, and tocilizumab in adults with rheumatoid arthritis and inadequate response to TNF inhibitors: prospective cohort study. BMJ 2019;364:167.

101 Smolen JS, Kay J, Doyle MK, et al. Golimumab in patients with active rheumatoid arthritis after treatment with tumour necrosis factor alpha inhibitors (GO-AFTER study): a multicentre, randomised, double-blind, placebo-controlled, phase III trial. Lancet 2009:374:210-21.

102 Weinblatt ME, Fleischmann R, Huizinga TWJ, et al. Efficacy and safety of certolizumab pegol in a broad population of patients with active rheumatoid arthritis: results from the realistic phase IIIB study. Rheumatology 2012;51:2204-14.

103 Smolen JS, Burmester G-R, Combe B, et al. Head-To-Head comparison of certolizumab pegol versus adalimumab in rheumatoid arthritis: 2-year efficacy and safety results from the randomised EXXELERATE study. The Lancet 2016;388:2763-74.

104 Verschueren P, Emery P, van Hoogstraten $H$, et al. THU0215 efficacy of sarilumab in patients with rheumatoid arthritis with and without previous response to tocilizumab. Ann Rheum Dis 2018;77:A327.

105 Fleischmann RM, Genovese MC, Enejosa JV, et al. Safety and effectiveness of upadacitinib or adalimumab plus methotrexate in patients with rheumatoid arthritis over 48 weeks with switch to alternate therapy in patients with insufficient response. Ann Rheum Dis 2019;78:1454-62.
106 Genovese MC, Kremer J, Zamani 0, et al. Baricitinib in patients with refractory rheumatoid arthritis. N Engl J Med 2016;374:1243-52.

107 Takeuchi T, Genovese MC, Haraoui B, et al. Dose reduction of baricitinib in patients with rheumatoid arthritis achieving sustained disease control: results of a prospective study. Ann Rheum Dis 2019;78:171-8.

108 Tanaka Y, Hirata S, Saleem B, et al. Discontinuation of biologics in patients with rheumatoid arthritis. Clin Exp Rheumatol 2013;31:S22-7.

109 Tanaka Y, Takeuchi T, Mimori T, et al. Discontinuation of infliximab after attaining low disease activity in patients with rheumatoid arthritis: RRR (remission induction by remicade in RA) study. Ann Rheum Dis 2010;69:1286-91.

110 Tanaka Y, Hirata S, Kubo S, et al. Discontinuation of adalimumab after achieving remission in patients with established rheumatoid arthritis: 1-year outcome of the honor study. Ann Rheum Dis 2015;74:389-95.

111 Tanaka Y, Smolen JS, Jones $\mathrm{H}$, et al. The effect of deep or sustained remission on maintenance of remission after dose reduction or withdrawal of etanercept in patients with rheumatoid arthritis. Arthritis Res Ther 2019;21:164.

112 Smolen JS, Szumski A, Koenig AS, et al. Predictors of remission with etanerceptmethotrexate induction therapy and loss of remission with etanercept maintenance, reduction, or withdrawal in moderately active rheumatoid arthritis: results of the preserve trial. Arthritis Res Ther 2018;20:8.

113 Tweehuysen L, van den Ende CH, Beeren FMM, et al. Little evidence for usefulness of biomarkers for predicting successful dose reduction or discontinuation of a biologic agent in rheumatoid arthritis: a systematic review. Arthritis Rheumatol 2017;69:301-8.

114 Smolen JS, Pedersen $\mathrm{R}$, Jones $\mathrm{H}$, et al. Impact of flare on radiographic progression after etanercept continuation, tapering or withdrawal in patients with rheumatoid arthritis. Rheumatology 2020;59:153-64.

115 Bouman CAM, den Broeder AA, van der Maas A, et al. What causes a small increase in radiographic progression in rheumatoid arthritis patients tapering TNF inhibitors? RMD Open 2017;3:e000327

116 van Mulligen E, de Jong PHP, Kuijper TM, et al. Gradual tapering TNF inhibitors versus conventional synthetic DMARDs after achieving controlled disease in patients with rheumatoid arthritis: first-year results of the randomised controlled tara study. Ann Rheum Dis 2019;78:746-53.

117 ten Wolde S, Breedveld FC, Dijkmans BAC, et al. Randomised placebo-controlled study of stopping second-line drugs in rheumatoid arthritis. The Lancet 1996;347:347-52.

118 ten Wolde S, Hermans J, Breedveld FC, et al. Effect of resumption of second line drugs in patients with rheumatoid arthritis that flared up after treatment discontinuation. Ann Rheum Dis 1997;56:235-9.

119 Duru N, van der Goes MC, Jacobs JWG, et al. EULAR evidence-based and consensusbased recommendations on the management of medium to high-dose glucocorticoid therapy in rheumatic diseases. Ann Rheum Dis 2013;72:1905-13.

120 del Rincón I, Battafarano DF, Restrepo JF, et al. Glucocorticoid dose thresholds associated with all-cause and cardiovascular mortality in rheumatoid arthritis. Arthritis \& Rheumatology 2014;66:264-72.

121 van Staa TP, Leufkens HGM, Abenhaim L, et al. Oral corticosteroids and fracture risk: relationship to daily and cumulative doses. Rheumatology 2000;39:1383-9.

122 Aletaha D, Maa J-F, Chen S, et al. Effect of disease duration and prior diseasemodifying antirheumatic drug use on treatment outcomes in patients with rheumatoid arthritis. Ann Rheum Dis 2019;78:1609-15.

123 Landewé RBM. Overdiagnosis and overtreatment in rheumatology: a little caution is in order. Ann Rheum Dis 2018;77:1394-6.

124 Roodenrijs NMT, de Hair MJH, van der Goes MC, et al. Characteristics of difficultto-treat rheumatoid arthritis: results of an international survey. Ann Rheum Dis 2018;77:1705-9.

125 Bécède M, Alasti F, Gess I , et al. Risk profiling for a refractory course of rheumatoid arthritis. Semin Arthritis Rheum 2019:49:211-7.

126 Winthrop KL, Weinblatt ME, Crow MK, et al. Unmet need in rheumatology: reports from the targeted therapies meeting 2018. Ann Rheum Dis 2019;78:872-8. 